\title{
Electrophysiological and Morphological Characteristics and Synaptic Connectivity of Tyrosine Hydroxylase-Expressing Neurons in Adult Mouse Striatum
}

\author{
Osvaldo Ibáñez-Sandoval, Fatuel Tecuapetla, Bengi Unal, Fulva Shah, Tibor Koós, and James M. Tepper \\ Center For Molecular and Behavioral Neuroscience, Rutgers, The State University of New Jersey, Newark, New Jersey 07102
}

\begin{abstract}
Whole-cell recordings were obtained from tyrosine hydroxylase-expressing $\left(\mathrm{TH}^{+}\right)$neurons in striatal slices from bacterial artificial chromosome transgenic mice that synthesize enhanced green fluorescent protein (EGFP) selectively in neurons expressing TH transcriptional regulatory sequences. Stereological cell counting indicated that there were $\sim 2700 \mathrm{EGFP}-\mathrm{TH}^{+}$neurons/striatum. Whole-cell recordings in striatal slices demonstrated that EGFP- $\mathrm{TH}^{+}$neurons comprise four electrophysiologically distinct neuron types whose electrophysiological properties have not been reported previously in striatum. EGFP- $\mathrm{TH}^{+}$neurons were identified in retrograde tracing studies as interneurons. Recordings from synaptically connected pairs of EGFP- $\mathrm{TH}^{+}$interneurons and spiny neurons showed that the interneurons elicited GABAergic IPSPs/IPSCs in spiny neurons powerful enough to significantly delay evoked spiking. EGFP-TH ${ }^{+}$ interneurons responded to local or cortical stimulation with glutamatergic EPSPs. Local stimulation also elicited $\mathrm{GABA}_{\mathrm{A}}$ IPSPs, at least some of which arose from identified spiny neurons. Single-cell reverse transcription-PCR showed expression of VMAT1 in EGFP-TH ${ }^{+}$ interneurons, consistent with previous suggestions that these interneurons may be dopaminergic as well as GABAergic. All four classes of interneurons were medium sized with modestly branching, varicose dendrites, and dense, highly varicose axon collateral fields. These data show for the first time that there exists in the normal rodent striatum a substantial population of $\mathrm{TH}^{+} / \mathrm{GABAergic}$ interneurons comprising four electrophysiologically distinct subtypes whose electrophysiological properties differ significantly from those of previously described striatal GABAergic interneurons. These interneurons are likely to play an important role in striatal function through fast GABAergic synaptic transmission in addition to, and independent of, their potential role in compensation for dopamine loss in experimental or idiopathic Parkinson's disease.
\end{abstract}

\section{Introduction}

The neostriatum is composed almost entirely of GABAergic neurons. The vast majority of these, commonly assumed to total $~ 95 \%$ of striatal neurons in rodents (Graveland and DiFiglia, 1985; Gerfen and Wilson, 1996), are medium-sized spiny projection neurons (SPNs) that represent both the major input and the only output from the striatum. The remaining neurons consist of large aspiny cholinergic interneurons, and at least three electrophysiologically distinct types of GABAergic interneurons (Kawaguchi, 1993; Kawaguchi et al., 1995; Tepper and Bolam, 2004). Despite being present in very small numbers, striatal interneurons have a profound effect on striatal functioning. Cholinergic interneurons exert a critically important neuromodulatory role in SPNs (Nishi et al., 1990; Kitai and Surmeier, 1993; Calabresi et al., 2000). In contrast, GABAergic interneurons, in particular the parvalbumin-immuno-

Received Dec. 3, 2009; revised March 23, 2010; accepted March 26, 2010.

This research was supported, in part, by National Institutes of Health Grants NSO34865 (J.M.T.) and NS052370 (T.K.), Consejo Nacional de Ciencia y Tecnología (0.I.-S.), and Rutgers University. We thank Drs. Elizabeth D. Abercrombie and Denis Paré for generously allowing us the use of their microscopes and image acquisition and analysis software for the cell counting and colocalization experiments, and Harry Xenias for comments on this manuscript.

Correspondence should be addressed to Dr. James M. Tepper, Center For Molecular and Behavioral Neuroscience, Rutgers, The State University of New Jersey, 197 University Avenue, Newark NJ 07102. E-mail: jtepper@ andromeda.rutgers.edu.

D0I:10.1523/JNEUROSCI.5996-09.2010

Copyright $\odot 2010$ the authors $\quad 0270-6474 / 10 / 306999-18 \$ 15.00 / 0$ reactive $\left(\mathrm{PV}^{+}\right)$fast-spiking $(\mathrm{FSI})$ and low-threshold $\mathrm{Ca}^{2+}$ spiking (LTS) interneurons, have been shown to be the principal source of strong, fast synaptic inhibition in striatum (Koós and Tepper, 1999; Koós et al., 2004; Tepper et al., 2004, 2008; Taverna et al., 2007), whereas the spiny cell axon collaterals, once believed to comprise a large and powerful lateral inhibitory network (Groves, 1983), exert surprisingly weak synaptic effects at the level of the SPN somata (Tunstall et al., 2002; Koós et al., 2004; Tecuapetla et al., 2009) (but see Wickens et al., 2007) but likely play key roles in regulating dendritic events and overall spiny cell excitability.

Classically, there are three subtypes of GABAergic interneurons in the neostriatum that can be distinguished neurochemically. One expresses the peptides somatostatin (SOM) and neuropeptide Y (NPY) and the enzymes NADPH diaphorase and nitric oxide synthase (NOS). The other two express the calcium binding proteins PV or calretinin (CR) (Kawaguchi, 1993; Kawaguchi et al., 1995). Together, these GABAergic interneurons comprise $\sim 2 \%$ of the rodent neostriatal cell population (Rymar et al., 2004).

However, Dubach et al. (1987) described a population of tyrosine hydroxylase-immunoreactive $\left(\mathrm{TH}^{+}\right)$neurons adult monkey striatum. Subsequently, striatal $\mathrm{TH}^{+}$neurons were found in several other species, including rat (Tashiro et al., 1989a,b; Meredith et al., 1999; O’Byrne et al., 2000), mouse (Mao et al., 2001; Petroske et al., 2001), monkey (Betarbet et al., 1997; 
Mazloom and Smith, 2006), and man (Cossette et al., 2005). In many reports, the $\mathrm{TH}^{+}$neurons were also shown to express the dopamine transporter (DAT), leading some authors to infer that these neurons were dopaminergic (Betarbet et al., 1997; Porritt et al., 2000, 2006; Palfi et al., 2002; Cossette et al., 2005; Huot et al., 2007; San Sebastián et al., 2007). Because these neurons have never been recorded from or intracellularly labeled, almost nothing is known about their synaptic connectivity or detailed somatodendritic or axonal morphology. We used a bacterial artificial chromosome (BAC) transgenic mouse strain that expresses enhanced green fluorescent protein (EGFP) (Gong et al., 2003) controlled by endogenous $\mathrm{TH}$ regulatory factors to identify these neurons in adult brain slices and obtain whole-cell recordings. Our results show that there are four electrophysiologically distinct types of striatal $\mathrm{TH}^{+}$neurons that are well integrated into the functional synaptic organization of the neostriatum.

Parts of this work have been reported previously in abstract form (Ibáñez-Sandoval et al., 2007, 2008).

\section{Materials and Methods}

Subjects. All subjects were Tg(Th-EGFP) 1 Gsat/MNmnc transgenic mice (hereafter referred to as EGFP-TH ${ }^{+}$mice), bred in our colony at Rutgers from stock obtained from Mutant Mouse Regional Resource Centers at University of California, Los Angeles from mice originally derived from GENSAT (for Gene Expression Nervous System Atlas; http://www.mmrrc. org/strains/292/0292.html). These mice contain multiple copies of a modified BAC containing the TH gene in which the TH mRNA and protein coding sequences were replaced by sequences encoding the EGFP reporter gene. The modified BAC was injected into pronuclei of FVB/N fertilized oocytes (Gong et al., 2007). Hemizygous progeny were mated to FVB mice each generation thereafter. All offspring were genotyped from blood samples obtained from the saphenous vein, and only those expressing the EGFP transgene were used in these experiments.

All procedures were performed with the approval of the Rutgers University Institutional Animal Care and Use Committee and in accordance with the National Institutes of Health Guide to the Care and Use of Laboratory Animals.

Preparation of brain slices. All experiments were performed on brain slices obtained from adult EGFP- $\mathrm{TH}^{+}$mice ranging in age from $28 \mathrm{~d}$ to 5 months. Most of the slices were taken from mice between 2 and 4 months of age. Mice were deeply anesthetized with $150 \mathrm{mg} / \mathrm{kg}$ ketamine and $30 \mathrm{mg} / \mathrm{kg}$ xylazine intraperitoneally and transcardially perfused with ice-cold, modified Ringer's solution containing the following (in $\mathrm{mM}$ ): 248 sucrose, $2.5 \mathrm{KCl}, 7 \mathrm{MgCl}_{2}, 23 \mathrm{NaHCO}_{3}, 1.2 \mathrm{NaH}_{2} \mathrm{PO}_{4}, 7$ glucose, 1 ascorbate, and 3 pyruvate, $\mathrm{pH} 7.3$ (bubbled with $95 \% \mathrm{O}_{2}$ and $5 \% \mathrm{CO}_{2}$ ). The brain was quickly removed into a beaker containing ice-cold oxygenated Ringer's solution and trimmed to a block containing the striatum. Coronal or parahorizontal sections $(250-350 \mu \mathrm{m})$ were cut in the same medium using a Vibratome 3000 and immediately transferred to normal Ringer's solution [containing in mM: $124 \mathrm{NaCl}, 2.5 \mathrm{KCl}, 1.2$ $\mathrm{NaH}_{2} \mathrm{PO}_{4}, 26 \mathrm{NaHCO}_{3}, 1.3 \mathrm{MgCl}_{2}, 2 \mathrm{CaCl}_{2}, 10$ glucose, 1 ascorbate, 3 pyruvate, and 0.4 myo-inositol, $\mathrm{pH} 7.3$ (heated to $34^{\circ} \mathrm{C}$ and continuously bubbled with $95 \% \mathrm{O}_{2}$ and $5 \% \mathrm{CO}_{2}$ )] for $1 \mathrm{~h}$ before recording and then maintained at room temperature until use. Slices were transferred to the recording chamber and submerged in continuously flowing oxygenated buffer $(2-4 \mathrm{ml} / \mathrm{min})$, which was heated to $\sim 34^{\circ} \mathrm{C}$.

Fluorescence and differential interference contrast imaging and recording. Slices were initially visualized under epifluorescence illumination with a high-sensitivity digital frame transfer camera (Cooke SensiCam) mounted on an Olympus BX50-WI epifluorescence microscope and a $40 \times$ long working distance water-immersion lens. Once an EGFP-TH ${ }^{+}$ neuron was identified, visualization was switched to infrared differential interference contrast (DIC) microscopy for the actual patching of the neuron, usually performed under current clamp.

Micropipettes for whole-cell recording were constructed from $1.5 \mathrm{~mm}$ outer diameter borosilicate pipettes (WPI) on a Narishige PP-83 vertical puller. The standard internal solution for whole-cell current-clamp re- cording contained the following (in $\mathrm{mm}$ ): $130 \mathrm{~K}$-gluconate, $10 \mathrm{NaCl}, 2$ $\mathrm{MgCl}_{2}, 10$ HEPES, $3 \mathrm{Na}_{2} \mathrm{ATP}, 0.3 \mathrm{GTP}$, and 1 EGTA, pH 7.3-7.4 (plus $0.1-0.3 \%$ biocytin). These pipettes had a direct current impedance of 4-6 M $\Omega . E_{[\mathrm{Cl}]}=-58 \mathrm{mV}$ at $35^{\circ} \mathrm{C}$ (Koós and Tepper, 1999). In some experiments, for recording of synaptically connected neuron pairs, $\mathrm{K}$-gluconate was replaced by $\mathrm{CsMeSO}_{4}$ in the internal for the postsynaptic neuron that also contained $25 \mu \mathrm{M}$ Alexa 594 (Invitrogen) to help visualize the axonal and/or dendritic arborization of presynaptic and/or postsynaptic neurons.

For most voltage-clamp recordings, the internal solution contained the following (in mM): $125 \mathrm{CsMeSO}_{4}, 16 \mathrm{~K}$-gluconate, $2 \mathrm{MgCl}_{2}, 10$ HEPES, $3 \mathrm{Na}_{2}$ ATP, $0.3 \mathrm{Na}_{3}$ GTP, 1 EGTA, $0.1 \mathrm{CaCl}_{2}$, and usually $5 \mathrm{~mm}$ QX-314 [2(triethylamino)- $N$-(2,6-dimethylphenyl) acetamine] (Sigma), $\mathrm{pH}$ 7.3-7.4. This had the effect of minimizing the effects of synapse location on the size of the IPSC and made small synaptic responses in striatal SPNs approximately three times larger and consequently easier to detect (Koós et al., 2004). Biocytin (0.1-0.5\%) was also added to the internal solution in most cases. Current-clamp recordings were made with a Neurodata IR-283 current-clamp amplifier whose output was digitized at $20-40 \mathrm{kHz}$ with a CED Micro $1401 \mathrm{Mk}$ II and a personal computer running Signal version 4 or 5 (Cambridge Electronic Design).

Voltage-clamp recordings were obtained with $3.5-6 \mathrm{M} \Omega$ pipettes and digitized with a Multiclamp 700B (Molecular Devices) running Axograph 1.2 or an EPC-9 (HEKA) and transferred to a Macintosh PowerPC (Apple Computers). The membrane potential of the postsynaptic neuron was clamped at $-70 \mathrm{mV}$. Series resistance compensation of $30-60 \%$ was used, and recordings were filtered online with a second-order Bessel filter at $1 \mathrm{kHz}$ and digitized at $10 \mathrm{kHz}$. During paired recording experiments, presynaptic neurons were stimulated at $0.5 \mathrm{~Hz}$ with single pulses, double pulses (20-50 ms interpulse interval), or short trains of 10 pulses at $10-50 \mathrm{~Hz}$.

At the completion of the experiments, slices containing biocytininjected neurons were fixed by immersion in $4 \%$ paraformaldehyde$0.5 \%$ glutaraldehyde for $30 \mathrm{~min}$ at room temperature or microwaved to $60^{\circ} \mathrm{C}$ for $10 \mathrm{~s}$ and stored overnight at $4^{\circ} \mathrm{C}$.

Extracellular stimulation. Stimulating electrodes consisted of bipolar enamel/nylon-coated 100- $\mu$ m-diameter stainless steel wires (California Fine Wire). The tips of the electrodes were stripped of insulation and separated by $100-500 \mu \mathrm{m}$. For local striatal stimulation, electrodes were placed onto the surface of the slice within $500 \mu \mathrm{m}$ of the recorded cell(s). For cortical stimulation, the electrodes were placed onto the surface of the deep layers of the cortex just rostral to the anterior pole of the neostriatum. Stimuli consisted of single square-wave pulses (typically $0.01-1$ $\mathrm{mA}, 0.1-0.3 \mathrm{~ms}$ duration at $0.1-0.5 \mathrm{~Hz}$ ) or brief trains consisting of 5-10 pulses delivered at $50-100 \mathrm{~Hz}$ and were generated by a Winston A-65 timer and SC-100 constant-current stimulus isolation unit (Iribe et al., 1999; Lee and Tepper, 2007).

Biocytin histochemistry. Slices containing biocytin-filled neurons were transferred into $4 \%$ paraformaldehyde overnight. In some cases, the thick sections were resectioned on a vibratome at $60 \mu \mathrm{m}$. Sections were washed three times for $10 \mathrm{~min}$ in $0.1 \mathrm{M}$ phosphate buffer (PB), followed by $10 \%$ methanol and $3 \% \mathrm{H}_{2} \mathrm{O}_{2}$ for $15 \mathrm{~min}$, and incubated with avidinbiotin-peroxidase complex (1:200; Vector Laboratories) and $0.1 \%$ Triton X-100 overnight at $4^{\circ} \mathrm{C}$. After washing six times for $10 \mathrm{~min}$ in $0.1 \mathrm{M}$ $\mathrm{PB}$, the sections were reacted with $3,-3^{\prime}$-diaminobenzidine (DAB) $(0.025 \%)$ and $\mathrm{H}_{2} \mathrm{O}_{2}(0.0008 \%)$ in $\mathrm{PB}$. In some cases, nickel intensification (Adams, 1981) was used (2.5 mm nickel ammonium sulfate and 7 $\mathrm{mM}$ ammonium chloride in the $\mathrm{DAB}$ and $\mathrm{H}_{2} \mathrm{O}_{2}$ incubation). The sections were then postfixed in osmium tetroxide $(0.1 \%$ in $\mathrm{PB})$ for $30 \mathrm{~min}$, dehydrated through a graded series of ethanol, followed by propylene oxide, and infiltrated overnight with a mixture of propylene oxide and epoxy resin (Durcupan; Fluka). The sections were then transferred to fresh resin mixture for several hours, flat embedded between glass slides and coverslips, and polymerized at $60^{\circ} \mathrm{C}$ for $24 \mathrm{~h}$.

Intrastriatal colchicine injection. To increase the intensity of TH immunolabeling in striatal neurons, three mice were anesthetized with isoflurane (one EGFP- $\mathrm{TH}^{+}$and two EGFP-TH ${ }^{-}$) and mounted in a stereotaxic apparatus. Subcutaneous bupivacaine (0.5\%; Henry Schein) was injected under the scalp and an incision was made. Small burr holes 
A

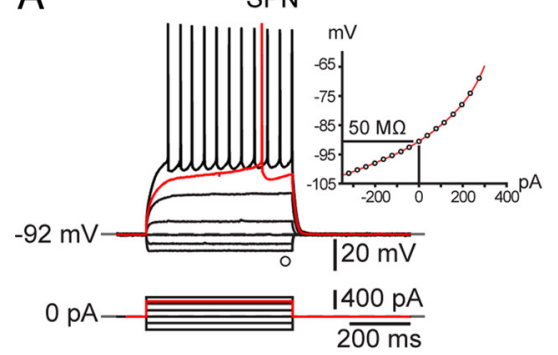

D

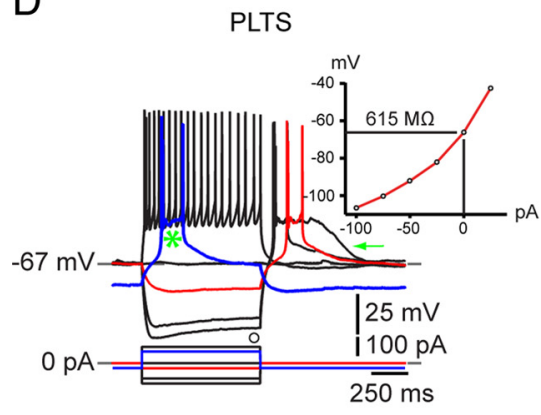

B

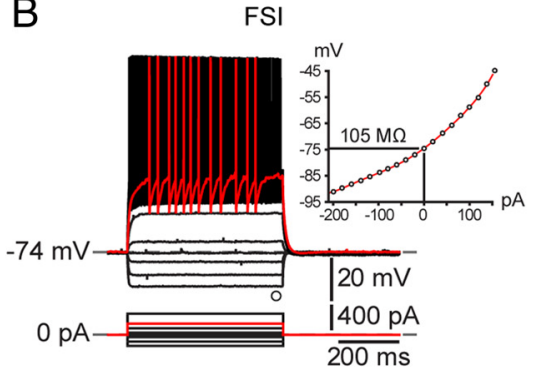

E

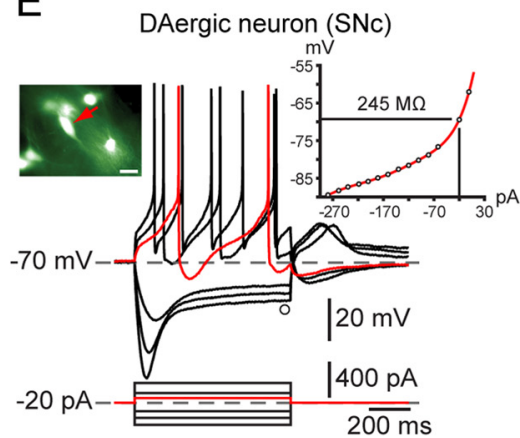

C

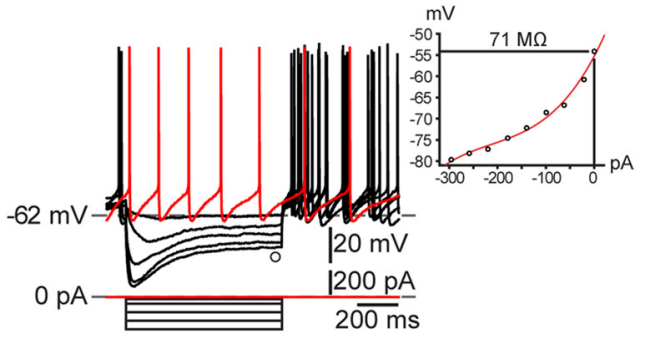

$\mathrm{F}$

G

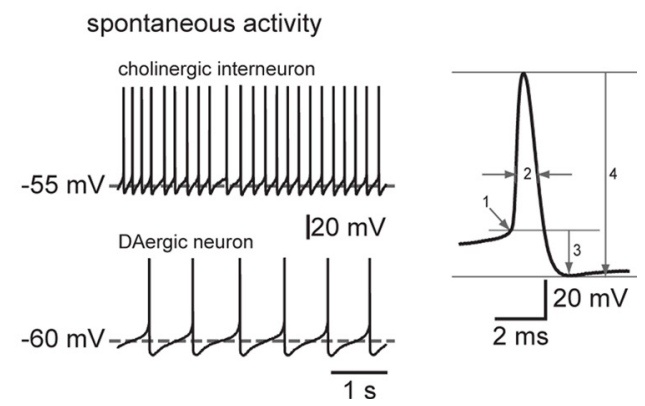

Figure 1. Electrophysiological properties of neostriatal and substantia nigra pars compacta neurons from BAC transgenic EGFP-TH ${ }^{+}$mice. $\boldsymbol{A}$, Typical striatal SPN. Note the extremely low input resistance, strong inward rectification, lack of spontaneous activity, and depolarizing ramp in response to depolarizing current pulse leading to delayed spiking (red trace). $\boldsymbol{B}$, FSI characterized by relatively low input resistance, lack of spontaneous activity, nonlinear spiking in response to depolarizing current pulses, high maximal firing frequency, and large spike afterhyperpolarizations. $\boldsymbol{C}$, Cholinergic interneurons were characterized by their spontaneous activity $(\boldsymbol{F}$, top trace and red trace in $\boldsymbol{C}$ ) and marked time-dependent sag in response to hyperpolarizing current injections attributable to activation of HCN channels. D, PLTS interneurons exhibited high input resistance and both low-threshold spike and plateau potential (arrow) at the offset of negative current injections. None of these neurons was EGFP ${ }^{+}$, and all exhibited characteristics identical to those described previously for electrophysiologically and neurochemically identified neurons in striatal slices from rat and mouse. $\boldsymbol{E}$, Typical responses of a substantia nigra pars compacta (SNc) dopaminergic neuron, fluorescent for EGFP-TH ${ }^{+}$(red arrow in inset). EGFP-TH ${ }^{+}$nigral dopaminergic neurons exhibit slow regular spontaneous activity $(\boldsymbol{F}$, bottom trace), long-duration action potentials, and a large time-dependent sag in response to hyperpolarizing current injections attributable to HCN. G, Single action potential from a SPN used to illustrate methods for measurements of action potential threshold (1), action potential duration at half-amplitude (2), afterhyperpolarization (3), and action potential amplitude (4). Scale bar in inset and Figs. 3-6, $20 \mu \mathrm{m}$.

were drilled in the skull overlying the striatum. Glass micropipettes were pulled from $1.2 \mathrm{~mm}$ capillary tubing, and the tips were broken back to a diameter of $\sim 50 \mu \mathrm{m}$ under microscopic control. Pipettes were filled $10-25 \mathrm{mg} / \mathrm{ml}$ colchicine (catalog \#C9754; Sigma-Aldrich) in $0.9 \%$ sterile saline. A total volume of $0.5-1 \mu \mathrm{l}$ of colchicine (final dose of $0.3-0.85$ $\mathrm{mg} / \mathrm{kg}$ ) was pressure injected at 20 psi over 20 min per site at two to three different coordinates per striatum (respectively, from bregma: +1.3 , $+0.9,+0.5 \mathrm{~mm}$ anterior; 1.5, 1.8, $2.3 \mathrm{~mm}$ mediolateral; and 2.3, 2.5, 2.8 $\mathrm{mm}$ ventral from the dura). After completion of injections, the micropipettes were left in place for an additional $5 \mathrm{~min}$ to allow diffusion of the toxin before being slowly retracted. The incision on the scalp was sutured using surgical silk, and the wound was infiltrated with bupivicaine and bacitracin ointment. Animals were allowed to recover under a heat lamp and closely monitored. Animals were supplemented with $0.2 \mathrm{ml}$ of lactated Ringer's solution subcutaneously once daily after surgery, until decapitation.

Three to $7 \mathrm{~d}$ after injection, an overdose of ketamine/xylazine was administered, and mice were perfused intracardially with ice-cold artificial CSF ringer buffer, followed by ice-cold $4 \%$ paraformaldehyde in 0.1 M sodium phosphate buffer, $\mathrm{pH}$ 7.4. Mice were decapitated, and the brains were removed and left in fixative overnight before sectioning on a vibratome at $60 \mu \mathrm{m}$. Sections were then pretreated with $1 \%$ sodium borohydride, followed by $10 \%$ methanol and $3 \% \mathrm{H}_{2} \mathrm{O}_{2}$ in PBS before incubation in blocking solution containing $10 \%$ normal donkey serum (NDS), $3 \%$ bovine serum albumin (BSA), and $0.5 \%$ Triton X-100 for $4-5$ $\mathrm{h}$ at room temperature.

Immunocytochemistry. Sections were pretreated with $1 \%$ sodium borohydride, followed by $10 \%$ methanol and $3 \% \mathrm{H}_{2} \mathrm{O}_{2}$ in PBS before incubation in $10 \%$ normal goat serum, $2 \%$ bovine serum albumin, and $0.5 \%$ Triton X-100 for $1 \mathrm{~h}$. Sections were then incubated in a solution containing 1:1000 rabbit anti-PV (catalog \#24428; ImmunoStar) or
anti-CR polyclonal (catalog \#AB5054; Millipore Corporation) antibody, 1:1000 goat anti-neuronal NOS (nNOS) polyclonal antibody (catalog \#ab1376; Abcam), or 1:1500 rabbit anti-tyrosine hydroxylase polyclonal antibody (catalog \#AB152; Millipore Corporation) along with 1\% NDS, $1 \%$ BSA, and $0.1 \%$ Triton X-100 in PBS for $48 \mathrm{~h}$, first $24 \mathrm{~h}$ at room temperature and then later $24 \mathrm{~h}$ at $4^{\circ} \mathrm{C}$. After washing three times for 10 min each in PBS, sections were transferred to a solution containing 1:500 (PV, CR) donkey anti-rabbit IgG or 1:500 (NOS) donkey anti-goat IgG conjugated with Alexa 594 (\#A21207; Invitrogen), in PBS at room temperature for $4 \mathrm{~h}$ or $4^{\circ} \mathrm{C}$ overnight. After three washes for $10 \mathrm{~min}$ in PBS, sections were mounted in antifade solution, Vectashield hardest mounting medium (catalog \#H1400; Vector Laboratories), and observed using an Olympus BX60 microscope equipped with epifluorescence.

Retrograde labeling. Three adult EGFP- $\mathrm{TH}^{+}$adult mice were anesthetized with isoflurane and placed into a stereotaxic frame. Glass micropipettes were pulled from $1.2 \mathrm{~mm}$ capillary tubing. Tips were broken back under microscopic control to a diameter of $\sim 50 \mu \mathrm{m}$ and tip filled with rhodamine microspheres (Lumafluor). A volume of $0.1 \mu \mathrm{l}$ of the rhodamine microspheres was pressure injected (Picospritzer; Intracel) over 15 min bilaterally into the globus pallidus (GP) $(0.4 \mathrm{~mm}$ posterior and 1.7 $\mathrm{mm}$ lateral with respect to bregma and $3.5 \mathrm{~mm}$ ventral from the dura) and into substantia nigra pars reticulata $(3.4 \mathrm{~mm}$ posterior and $1.4 \mathrm{~mm}$ lateral with respect to bregma and $4.5 \mathrm{~mm}$ ventral from the dura). After the completion of each injection, the pipette was left in place for $3 \mathrm{~min}$ and then slowly withdrawn.

Four to $7 \mathrm{~d}$ after injection, animals were administered an overdose of ketamine/xylazine and transcardially perfused with chilled Ringer's solution, followed by $2 \%$ paraformaldehyde in $0.1 \mathrm{M} \mathrm{PB}$. Brains were kept overnight in $2 \%$ paraformaldehyde at $4^{\circ} \mathrm{C}$, subsequently transferred into PBS, and stored at $4^{\circ} \mathrm{C}$ until sectioned. Sixty micrometers frozen coronal sections containing striatum and the injection sites were cut on a sliding 
microtome (Microm), mounted on glass slides in Vectashield HardSet mounting medium (Vector Laboratories), and coverslipped. Sections were examined for colocalization of EGFP and rhodamine beads, and microphotographs were obtained on an Olympus BX-50 fluorescent microscope with a Retiga 2000R CCD camera (Q-Imaging) controlled by Stereo Investigator (MBF Bioscience).

Cell counting. A separate group of EGFP$\mathrm{TH}^{+}$mice $(n=3)$ underwent the same fixation, sectioning, and mounting procedures described above in preparation for unbiased stereological cell counting (West, 2002) using Stereo Investigator version 9 using the opticalfractionator method (MBF Bioscience). The first section was randomly determined by the default workflow of the software, and every fifth section was traced at $4 \times$ magnification for striatal volume estimation. A grid with a single frame size of $500 \times 900 \mu \mathrm{m}$ was superimposed over the traced region of interest, and counting frames were placed randomly by the software. Counting was performed with a $20 \times$ objective in which the counting frame size was set at $200 \times 200 \mu \mathrm{m}$ with an interframe distance of $300 \mu \mathrm{m}$, which yielded 10 counting sites per section on average. Disector height was set at $30 \mu \mathrm{m}$ with a $5 \%$ guard zone on top and bottom of the sampled volume of tissue. Striatal EGFP- $\mathrm{TH}^{+}$cell bodies falling within the counting frame borders and not touching the exclusion borders were marked under epifluorescence illumination at $485 \mathrm{~nm}$. Marked striatal EGFP- $\mathrm{TH}^{+}$somata were further investigated for colocalization of retrogradely transported rhodamine microspheres from globus pallidus and substantia nigra and substantia nigra pars reticulata under epifluorescence illumination at $530 \mathrm{~nm}$. These data were used to estimate the total number of EGFP-TH ${ }^{+}$only cells and double-labeled EGFP-TH ${ }^{+} /$rhodamine $^{+}$cells in striatum.

Single-cell multiplex reverse transcription-PCR analysis. In 10 cases at the completion of the recording experiment, the cytoplasm of the recorded neuron was aspirated into the recording micropipette, and the resulting material was used for multiplex reverse transcription (RT)-PCR analysis as described previously (Monyer and Lambolez, 1995; Surmeier et al., 1996) with modifications, including the addition of GTP and ATP to the recording solution as described in detail by Tecuapetla et al. (2009). Briefly, electrode holders and other relevant equipment were autoclaved or rinsed with RNase away (Invitrogen) and 100\% ethanol, and pipette glass was baked at $200^{\circ} \mathrm{C}$ for $>4 \mathrm{~h}$. Intracellular recording solutions were prepared carefully in RNase-free environment with RNase-free chemicals dedicated to this purpose and DEPC-treated water and had the same composition as for regular whole-cell recordings. Neuronal mRNA was collected by harvesting the cytoplasm by aspiration. The pipette contents were expelled into RNase-free $0.25 \mathrm{ml}$ PCR tubes containing $5 \mu$ l of DEPC-treated $\mathrm{H}_{2} 0,1 \mu \mathrm{l}$ of Superase RNase inhibitor (Ambion), $1 \mu \mathrm{l}$ of $0.1 \mathrm{M}$ dithiothreitol, and $1 \mu \mathrm{l}$ of oligo- $\mathrm{dT}_{12-18}$ primer (Invitrogen), briefly centrifuged, and stored at $-20^{\circ} \mathrm{C}$. Reverse transcription was performed as described by Tecuapetla et al. (2009). Multiplex PCR was performed with two rounds of amplification as described by Cauli et al. (1997) with the modification of including the first-round PCR pairs for VMAT1 and VMAT2 in the first PCR round and amplifying these two signals separately in the second round with the corresponding nested primer sets. The nested PCR strategy for vesicular monoamine transporter (VMAT) isoforms was chosen to increase specificity. The VMAT1 and VMAT2 primer pairs have been described and characterized by Graff et al. (2001). The PCR amplicons were analyzed with agarose gel electrophoresis.

Statistical analysis. Most numerical values are reported as the mean \pm SEM. Data were analyzed by using ANOVA with Prism (GraphPad Soft-
B
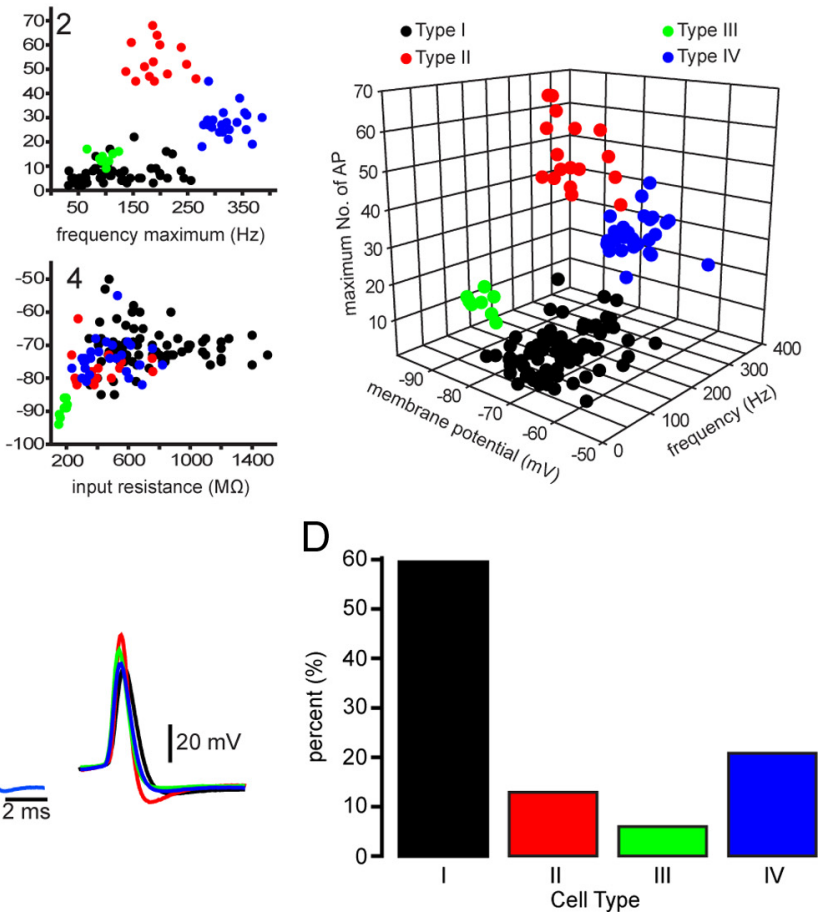

Four different types of EGFP-TH ${ }^{+}$neurons in mouse striatum. $\boldsymbol{A}$, Selected two-dimensional scatter plots of various 列 action potentials from cell Types I-IV clearly show differences in multiple spike waveform parameters. $\boldsymbol{D}$, Histogram showing the distribution of the four EGFP-TH ${ }^{+}$cell types.

ware), followed with Bonferroni's post hoc tests to compare individual group (type) means. Differences were considered to be significant if $p<0.05$.

\section{Results}

Electrophysiological properties of previously described striatal and nigral neuron types in EGFP-TH ${ }^{+}$BAC transgenic mice

In whole-cell recordings from striatal slices from adult EGFP$\mathrm{TH}^{+}$mice, neurons exhibiting the electrophysiological characteristics of SPNs, FSIs, cholinergic interneurons, and persistent low-threshold spiking (PLTS) interneurons described previously in normal mice and rats were readily encountered. Analysis of a subset of these neurons, none of which were EGFP-TH ${ }^{+}$, revealed that SPNs $(n=9)$ exhibited an input resistance of $57.3 \pm$ $6.6 \mathrm{M} \Omega$, a strongly hyperpolarized resting membrane potential of $-91.7 \pm 1.47 \mathrm{mV}$, an action potential threshold of $-43.1 \pm 1.0$ $\mathrm{mV}$, an action potential duration of $0.88 \pm 0.02 \mathrm{~ms}$ (measured at half-amplitude), and an action potential amplitude of $104.4 \pm$ $1.7 \mathrm{mV}$. These neurons showed delayed spiking to depolarizing current pulses, a marked inward rectification, did not fire spontaneously, and were indistinguishable in all respects from SPNs reported previously in normal adult wild-type mice and rats (Kita et al., 1984; Nisenbaum and Wilson, 1995; Wilson and Kawaguchi, 1996; Gertler et al., 2008). Similarly, FSIs $(n=8)$ exhibited an input resistance of $71.7 \pm 13.0 \mathrm{M} \Omega$, a more depolarized resting membrane potential of $-78.6 \pm 1.3 \mathrm{mV}$ but no spontaneous activity, an action potential threshold of $-41.3 \pm 1.08 \mathrm{mV}$, an action potential duration of $0.39 \pm 0.02 \mathrm{~ms}$ at half-amplitude, and an action potential amplitude of $78.2 \pm 2.0 \mathrm{mV}$ as reported previously (Kawaguchi, 1993; Koós and Tepper, 1999). Cholinergic interneurons $(n=8)$ exhibited an input resistance of $69 \pm 3.1 \mathrm{M} \Omega$, 
A

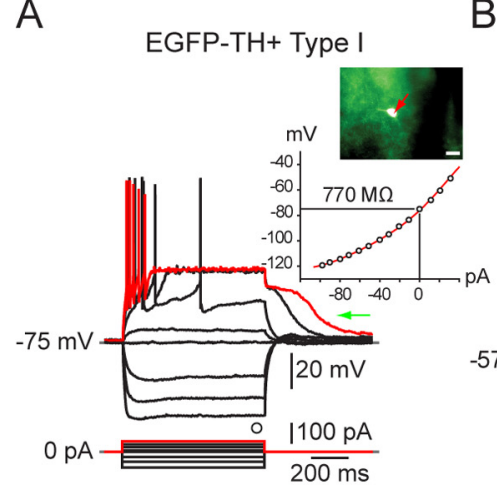

C

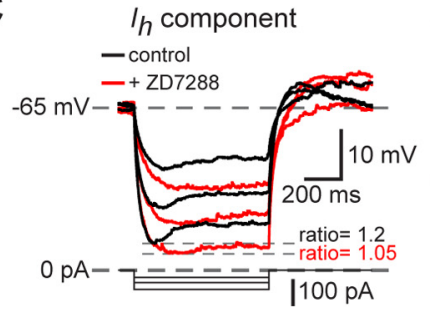

D rebound bursting

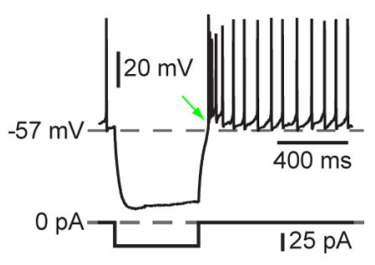

$E$

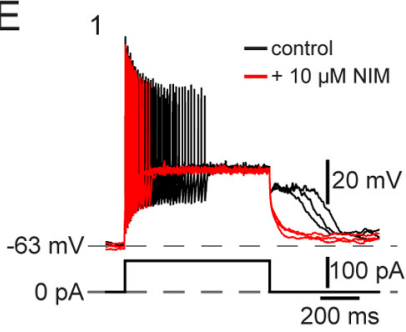

2

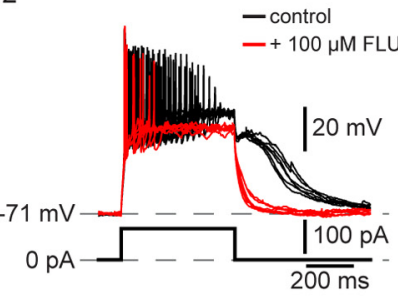

$\mathrm{F}$

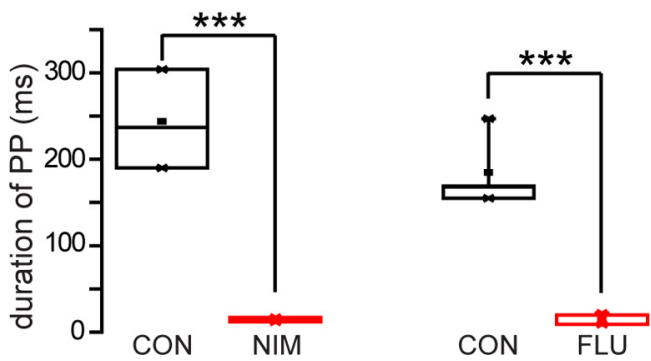

Figure 3. Electrophysiological properties of Type I EGFP-TH ${ }^{+}$neurons. $\boldsymbol{A}$, Whole-cell current-clamp recordings of responses to negative and positive current pulses in a Type I neuron show high input resistance, strong spike frequency adaptation leading to complete spike failure after small depolarizing pulses (red trace), and the expression of long-lasting plateau potentials (green arrow). Inset, EGFP fluorescent image of recorded neuron and $I-V$ plot showing inward rectification. $I-V$ curves in this and Figures $4-6$ are plotted at the end of the current pulse at the point marked by an open circle. $\boldsymbol{B}$, Some Type I neurons exhibited slow, irregular spontaneous activity characterized by $\sim 10 \mathrm{mV}$ fluctuations in membrane potential. C, Time-dependent sag in response to hyperpolarizing current injection and rebound slow depolarization after its offset (green arrow) are both blocked by ZD7288 $\left(50 \mu \mathrm{m}\right.$ ), indicating that both are attributable to $\mathrm{I}_{\mathrm{h}}$. D, Rebound bursting after offset of hyperpolarizing current injections. E1, The plateau potential was blocked by $10 \mu$ m nimodipine (NIM). E2, Plateau potential in a different Type I neuron is blocked by $100 \mu \mathrm{m}$ flufenamic acid (FLU), indicating that the plateau potentials are attributable to a $\mathrm{Ca}^{2+}$-activated cation conductance $\left(I_{\text {CAN }}\right)$. F1, Summary of effects of nimodipine on plateau potential (PP) duration in six Type I neurons. F2, Summary of effects of flufenamic acid on plateau potential (PP) duration in eight Type I neurons. CON, Control. ${ }^{* * *} p<0.0001$.

a depolarized resting membrane potential of $-55.3 \pm 1.28 \mathrm{mV}$, and fired spontaneously between -61 to $-48 \mathrm{mV}$ at $1.9 \pm 0.4 \mathrm{~Hz}$. Cholinergic interneurons exhibited an action potential threshold of $-44.4 \pm 1.15 \mathrm{mV}$, a spike duration of $1.77 \pm 0.12 \mathrm{~ms}$, and a marked time-dependent sag in response to hyperpolarizing current injec-
A

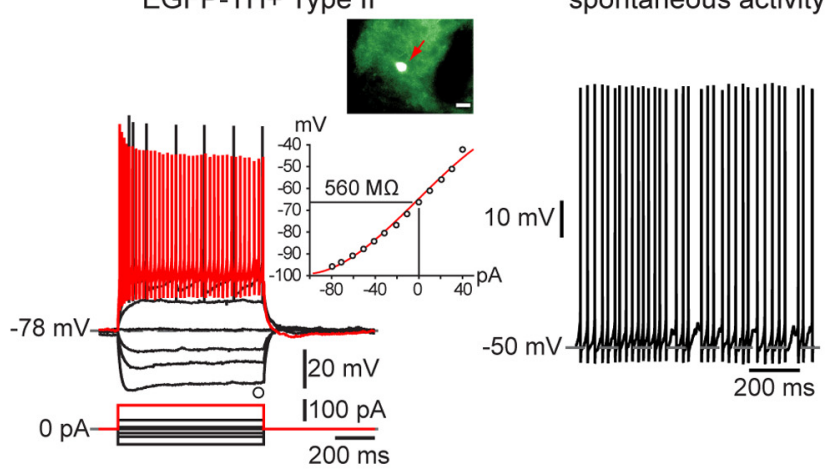

C

EGFP-TH+ Type III

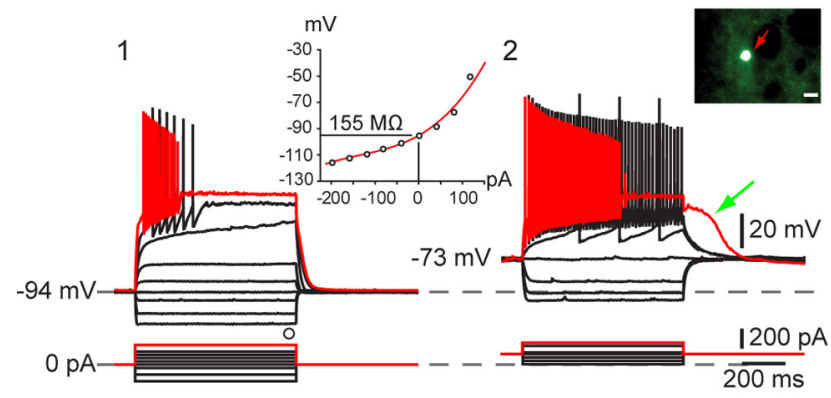

D

1

control

$2+10 \mu \mathrm{M}$ nimodipine

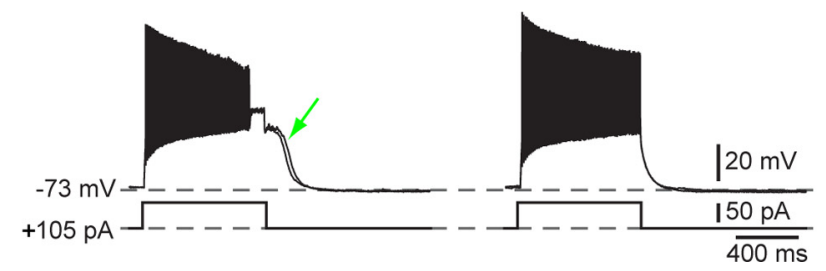

Figure 4. Electrophysiological properties of Type I and Type II EGFP-TH ${ }^{+}$neurons. A, Responses to negative and positive current pulses in a Type II neuron illustrate lower input resistance than Type I neurons, similar time-dependent $/ \mathrm{h}$-like sag in response to hyperpolarizing current injections, and ability to sustain high-frequency firing with little spike frequency adaptation after the first few milliseconds. Inset, EGFP fluorescent image of recorded neuron and $I-V$ plot showing almost linear responses except at most hyperpolarized membrane potentials. $B$, Example of tonic spontaneous firing. C, D, Electrophysiological properties of Type III EGFP$\mathrm{TH}^{+}$neurons. C1, Responses to negative and positive current pulses in a Type III neuron reveal a linear $I-V$ relationship below $-90 \mathrm{mV}$ and marked inward rectification at more depolarized potentials. Note the very low input resistance and the very hyperpolarized resting membrane potential compared with Type I and Type II neurons. There is significant spike frequency adaptation, leading to complete spike failure in responses to strongest depolarizing current pulses. C2, When Type III neurons are depolarized by constant current injection, overall excitability is increased, spike frequency adaptation is reduced allowing sustained firing up to $120 \mathrm{~Hz}$, and a prolonged plateau potential appears (green arrow). The plateau potential (D1) is blocked by 10 $\mu \mathrm{m}$ nimodipine (D2), demonstrating the involvement of an $\mathrm{L}$-type $\mathrm{Ca}^{2+}$ channel.

tions (Kawaguchi, 1993; Kawaguchi et al., 1995; Bennett et al., 2000). PLTS interneurons $(n=3)$ exhibited an input resistance of $562 \pm 30 \mathrm{M} \Omega$, a resting membrane potential of $-56 \pm 1 \mathrm{mV}$, an action potential threshold of $41 \pm 1 \mathrm{mV}$, a spike duration of $1.02 \pm 0.04 \mathrm{~ms}$, a marked time-dependent sag in response to hyperpolarizing current injections, and a rebound persistent lowthreshold spike and/or a prolonged plateau potential after the termination of hyperpolarizing current injections (Kawaguchi, 1993; Kawaguchi et al., 1995).

In substantia nigra pars compacta, dopaminergic neurons identified by EGFP-TH ${ }^{+}$fluorescence exhibited an input resis- 
tance of $258.5 \pm 44.4 \mathrm{M} \Omega$, a membrane potential that oscillated at $\sim 4 \mathrm{~Hz}$ around a mean of $-53.8 \pm 1.8 \mathrm{mV}$, spontaneous activity at $4.0 \pm 0.41 \mathrm{~Hz}$, an action potential threshold of $-38.75 \pm 0.25 \mathrm{mV}$, an action potential duration of $1.5 \pm 0.13 \mathrm{~ms}$ at half-amplitude, and an action potential amplitude of $61.95 \pm 0.86 \mathrm{mV}$, as reported previously (Kita et al., 1986; Grace and Onn, 1989; Iribe et al., 1999).

The electrophysiological characteristics of the four striatal neuron types and the substantia nigra dopaminergic neurons were both qualitatively and quantitatively similar or identical to those reported previously for similar recordings from adult wildtype rats and mice and show, first, that the BAC EGFP insertion has no effect on the basic electrophysiological properties of striatal or nigral neurons and, second, that the properties of these neurons in mice and rats are indistinguishable, at least for the parameters that we measured. Typical examples of in vitro whole-cell recordings from these neurons in brain slices from adult EGFP-TH ${ }^{+}$mice are shown in Figure 1.

\section{Electrophysiological properties of striatal EGFP $\mathrm{TH}^{+}$neurons}

Similar measurements in striatal EGFP- $\mathrm{TH}^{+}$neurons $(n=139$ of 300 total EGFP- $\mathrm{TH}^{+}$neurons recorded) revealed a surprisingly large variability in values for spontaneous activity, action potential waveform, input resistance, maximal evoked firing rate, and responses to hyperpolarizing and depolarizing current injections. It quickly became apparent that there were several electrophysiologically distinct types of striatal EGFP- $\mathrm{TH}^{+}$neuron. From the qualitative and quantitative features of the responses to hyperpolarizing and depolarizing current injections in currentclamp mode, there appeared to be four distinct types of striatal EGFP-TH ${ }^{+}$neurons. None of the four cell types resembled even slightly striatal SPNs, FSIs, cholinergic interneurons, or substantia nigra dopaminergic neurons.

For quantitative analysis, we first constructed a number of scatter plots in which the values for each of several measured variables were plotted against one another for each of the neurons. The resulting scatter plots were very informative, as shown in Figure 2. Although relations between two variables usually resulted in the clear separation or clustering of the neurons into two or sometimes three groups, collectively the different scatter plots supported our initial parcellation of striatal EGFP-TH ${ }^{+}$ neurons into four distinct cell types that we named EGFP-TH ${ }^{+}$ Types I-IV, as shown in Figure 2.

\section{Type I neurons}

Type I neurons were by far the most frequently encountered subtype of striatal EGFP-TH ${ }^{+}$neuron, making up $>60 \%$ of the striatal $\mathrm{TH}^{+}$neurons (84 of 139). Responses to current injection revealed that these neurons expressed an extremely high input resistance, $744 \pm 33 \mathrm{M} \Omega$ (range, 346-1500 M $\Omega$ ), and a modest, slow inward rectification to hyperpolarizing current injections (Fig. 3A). The mean resting membrane potential was the least hyperpolarized of all the EGFP- $\mathrm{TH}^{+}$neurons, at $-71 \pm 1 \mathrm{mV}$
B

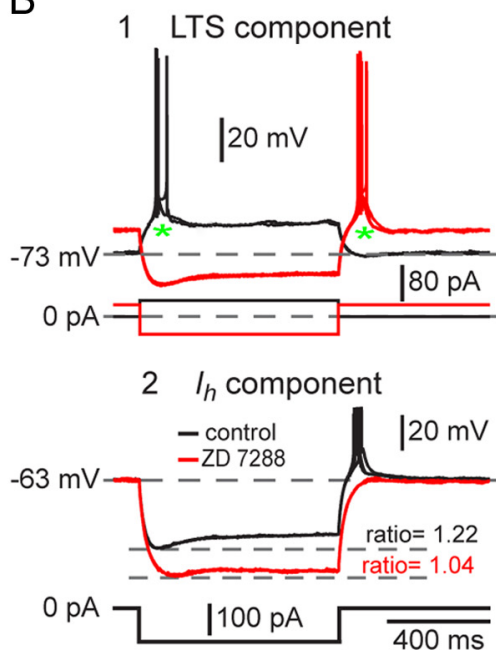

Figure 5. Electrophysiological properties of Type IV EGFP-TH ${ }^{+}$neurons. $\boldsymbol{A}$, Responses to negative and positive current pulses
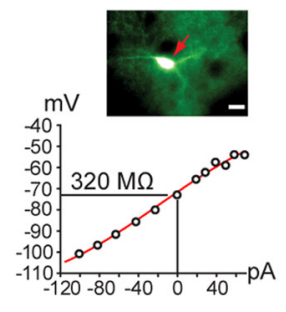

Type IV

$20 \mathrm{mV}$

$200 \mathrm{pA}$

$2 \overline{00 \mathrm{~ms}}$ 
Table 1. Electrophysiological properties of striatal EGFP-TH ${ }^{+}$interneurons in adult mice

\begin{tabular}{|c|c|c|c|c|}
\hline Parameter & Type I (84) & Type II (18) & Type III (8) & Type IV (29) \\
\hline Input resistance (M $\Omega$ ) & $\begin{array}{l}744 \pm 33^{a, b, c}(346 \text { to } 1500) \\
n=78\end{array}$ & $\begin{array}{l}429 \pm 39 \text { (234 to } 758) \\
n=17\end{array}$ & $\begin{array}{l}180 \pm 8^{f} \text { (150 to 205) } \\
n=8\end{array}$ & $\begin{array}{l}471 \pm 30 \text { (235 to 821) } \\
n=29\end{array}$ \\
\hline Resting membrane potential (mV) & $\begin{array}{l}-71 \pm 1^{a, b, c}(-50 \text { to }-85) \\
n=79\end{array}$ & $\begin{array}{l}-77 \pm 1^{d}(-62 \text { to }-82) \\
n=18\end{array}$ & $\begin{array}{l}-89 \pm 1(-86 \text { to }-94) \\
n=8\end{array}$ & $\begin{array}{l}-74 \pm 1^{f}(-55 \text { to }-82) \\
n=29\end{array}$ \\
\hline AP threshold (mV) & $\begin{array}{l}-43 \pm 0.3^{a}(-38 \text { to }-50) \\
n=81\end{array}$ & $\begin{array}{l}-47 \pm 0.5^{e}(-42 \text { to }-50) \\
n=17\end{array}$ & $\begin{array}{l}-45 \pm 0.6(-42 \text { to }-47) \\
n=8\end{array}$ & $\begin{array}{l}-44 \pm 0.5(-39 \text { to }-48) \\
n=29\end{array}$ \\
\hline AP width $50 \%$ (ms) & $\begin{array}{l}0.78 \pm 0.03^{a, b, c}(0.4 \text { to } 1.9) \\
n=81\end{array}$ & $\begin{array}{l}0.43 \pm 0.01(0.3 \text { to } 0.53) \\
n=17\end{array}$ & $\begin{array}{l}0.46 \pm 0.01(0.4 \text { to } 0.5) \\
n=8\end{array}$ & $\begin{array}{l}0.5 \pm 0.02(0.4 \text { to } 0.85) \\
n=29\end{array}$ \\
\hline AP amplitude (mV) & $\begin{array}{l}\quad 76 \pm 1.3^{a}(52 \text { to } 101) \\
n=81\end{array}$ & $\begin{array}{l}\quad 94 \pm 2^{d, e}(86 \text { to } 116) \\
n=17\end{array}$ & $\begin{array}{l}79 \pm 2(70 \text { to } 88) \\
n=8\end{array}$ & $\begin{array}{l}80 \pm 1(63 \text { to } 91) \\
n=29\end{array}$ \\
\hline AHP amplitude (mV) & $\begin{array}{l}16 \pm 0.4^{a}(7 \text { to } 24) \\
n=81\end{array}$ & $\begin{array}{l}\left.20 \pm 0.6^{d, e} \text { (16 to } 25\right) \\
n=17\end{array}$ & $\begin{array}{l}14 \pm 0.3(13 \text { to } 16) \\
n=8\end{array}$ & $\begin{array}{l}15 \pm 0.5(10 \text { to } 24) \\
n=29\end{array}$ \\
\hline Maximum number of AP (150-200 pA) & $\begin{array}{l}\quad 7 \pm 0.6^{a, b, c}(2 \text { to } 22) \\
n=53\end{array}$ & $\begin{array}{l}53 \pm 2^{d, e}(45 \text { to } 68) \\
n=14\end{array}$ & $\begin{array}{l}14 \pm 1^{f}(9 \text { to } 17) \\
n=8\end{array}$ & $\begin{array}{l}28 \pm 1(18 \text { to } 45) \\
n=23\end{array}$ \\
\hline Maximum frequency $(\mathrm{Hz})$ & $\begin{array}{l}114 \pm 9^{a, c}(32 \text { to } 256) \\
n=53\end{array}$ & $\begin{array}{l}194 \pm 10^{d, e}(137 \text { to } 265) \\
n=14\end{array}$ & $\begin{array}{l}\quad 98 \pm 6^{f}(66 \text { to } 124) \\
n=8\end{array}$ & $\begin{array}{l}321 \pm 6(276 \text { to } 386) \\
n=23\end{array}$ \\
\hline Spontaneous activity & 10 of 84 & 4 of 18 & 0 of 8 & 1 of 29 \\
\hline Plateau potential duration (ms) & $\begin{array}{l}255 \pm 31 \text { (46 to 1250) } \\
39 \text { of } 84\end{array}$ & $\begin{array}{l}150 \pm 116 \text { (15 to } 381) \\
3 \text { of } 12\end{array}$ & $\begin{array}{l}159 \pm 41 \text { (119 to 200) } \\
2 \text { of } 8\end{array}$ & 0 of 26 \\
\hline $\begin{array}{l}\text { LTS component } \\
I_{h} \text { ratio }\end{array}$ & $\begin{array}{l}0 \text { of } 84 \\
1.12 \pm 0.01 \text { (1.03 to } 1.54) \\
44 \text { of } 84\end{array}$ & $\begin{array}{l}4 \text { of } 18 \\
1.12 \pm 0.02 \text { (1.05 to } 1.2) \\
11 \text { of } 18\end{array}$ & 0 of 8 & $\begin{array}{l}29 \text { of } 29 \\
1.13 \pm 0.02 \text { (1.02 to } 1.3) \\
17 \text { of } 29\end{array}$ \\
\hline
\end{tabular}

All values are means \pm SEM. Numbers in parentheses refer to the range of values. $n$ refers to number of neurons from which the measurements were obtained. AP, Action potential; AHP, afterhyperpolarization. One-way ANOVA revealed a significant difference effect of type for all parametric measurements. Bonferroni's post hoc comparisons were run to determine specific type to type differences.

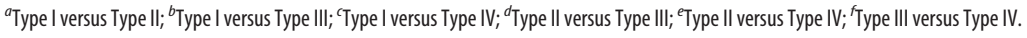

$a, b, c, d, e, f p<0.001$.

$a, b, c, d, e, f p<0.05$
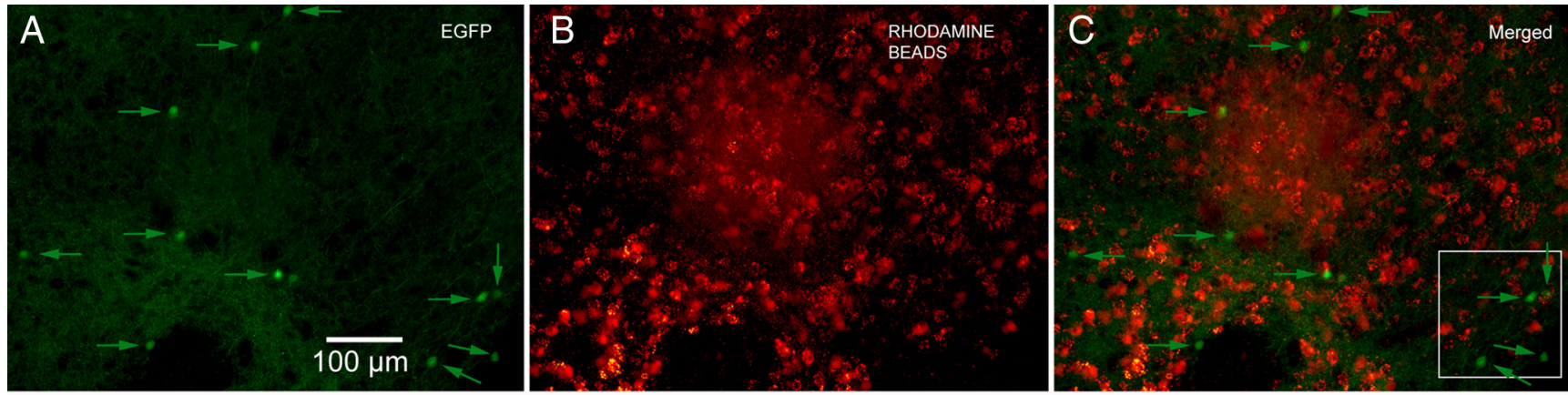

D

INJECTION SITES

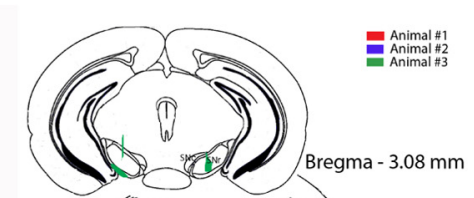

SN
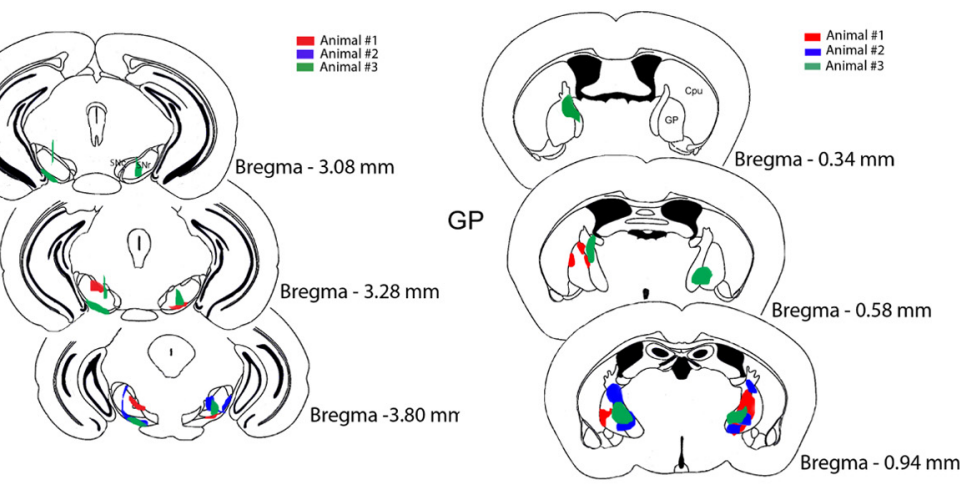

E

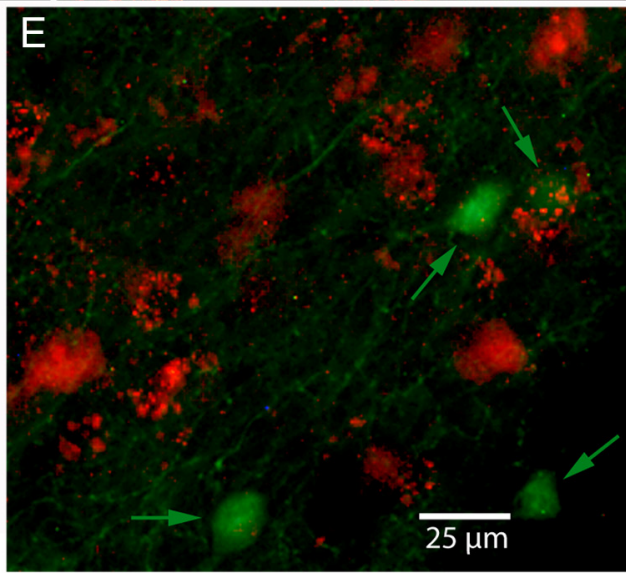

Figure 6. Retrograde labeling. $A$, Medium-magnification fluorescence micrograph of striatum after injections of rhodamine beads into both SN and GP under the EGFP filter. Eleven fluorescent EGFP-TH ${ }^{+}$neurons (arrows) are visible. $\boldsymbol{B}$, Same field as in $\boldsymbol{A}$ but under the rhodamine filter showing numbers fluorescent retrogradely labeled SPNs. $\boldsymbol{C}$, Merged image of $\boldsymbol{A}$ and $\boldsymbol{B}$. Note that there is no colocalization of EGFP and rhodamine. $\boldsymbol{D}$, Rhodamine injection sites in SN and GP for three animals. $\boldsymbol{E}$, Higher-magnification merged image of the area shown in the white square in $\boldsymbol{C}$ shows that none of the retrogradely labeled neurons express EGFP. 
The Type I neuron was clearly distinct from the PLTS interneuron described by Kawaguchi (1993). The NPY-containing PLTS neuron exhibits plateaus during depolarizing current injections and a rebound low-threshold spike after the offset of a hyperpolarizing pulse, whereas the Type I neuron exhibits neither of these but rather exhibits a long-lasting plateau potential after the offset of depolarizing current pulse as shown in Figure 3.

\section{Type II neurons}

Type II neurons were clearly distinct from Type I neurons. They exhibited a much lower input resistance $(429 \pm 39$ $\mathrm{M} \Omega$; range, 234-758 $\mathrm{M} \Omega$ ) and a relatively linear $I-V$ curve except for a slight inward rectification at very hyperpolarized membrane potentials. Spike duration was brief, $0.43 \pm 0.01 \mathrm{~ms}$ (range, $0.30-0.53 \mathrm{~ms}$ ), with a spike amplitude of $94 \pm 2 \mathrm{mV}$ (range, 86-116 mV). Type II neurons were readily classifiable as fast-spiking neurons and responded to depolarizing current injection with a mean sustained firing of $194 \pm 10 \mathrm{~Hz}$ (range, 137-265 $\mathrm{Hz}$ ), as illustrated for one typical example in Figure $4 A$. Although unquestionably a type of fast-spiking neuron, Type II neurons were clearly distinct from $\mathrm{PV}^{+}$FSIs by virtue of their much higher input impedance and lack of intermittent/burst firing in response to depolarizing current pulses. Type II neurons accounted for $13 \%$ (18 of 139) of the striatal EGFP$\mathrm{TH}^{+}$neurons and were the only other subtype of striatal EGFP-TH ${ }^{+}$neuron that exhibited spontaneous activity (4 of 18 neurons; $22 \%$ ), with a mean firing rate of $10.4 \pm 8 \mathrm{~Hz}$ (range, 2 to $24 \mathrm{~Hz}$ ), as shown in Figure $4 B$. The majority of these neurons (11 of 18) exhibited a timedependent sag in response to hyperpolarizing current injection similar to that of Type I neurons.

\section{Type III neurons}

Type III neurons exhibited the most hyperpolarized membrane potentials of the striatal EGFP-TH ${ }^{+}$neurons (resting membrane potential, $89 \pm 1 \mathrm{mV}$; range, -86 to $-94 \mathrm{mV}$ ) and exhibited the lowest input resistance ( $180 \pm 8 \mathrm{M} \Omega$; range, $150-205 \mathrm{M} \Omega$ ), primarily because of a strong inward rectification at membrane potentials more hyperpolarized than $-80 \mathrm{mV}$ (Fig. $4 C$ ). Type III neurons made up $\sim 6 \%$ of the striatal EGFP-TH ${ }^{+}$neurons and were not spontaneously active. Type III neurons did not fire spikes in response to depolarizing current injections administered from rest that depolarized the resting membrane potential as high as $-50 \mathrm{mV}$. Above this, however, a small increment in the intensity of the injected current resulted in a short burst of action potentials that exhibited strong spike frequency adaptation, accommodation and reduction in spike amplitude, followed by an abrupt cessation in spiking, similar to that seen in Type I neurons.
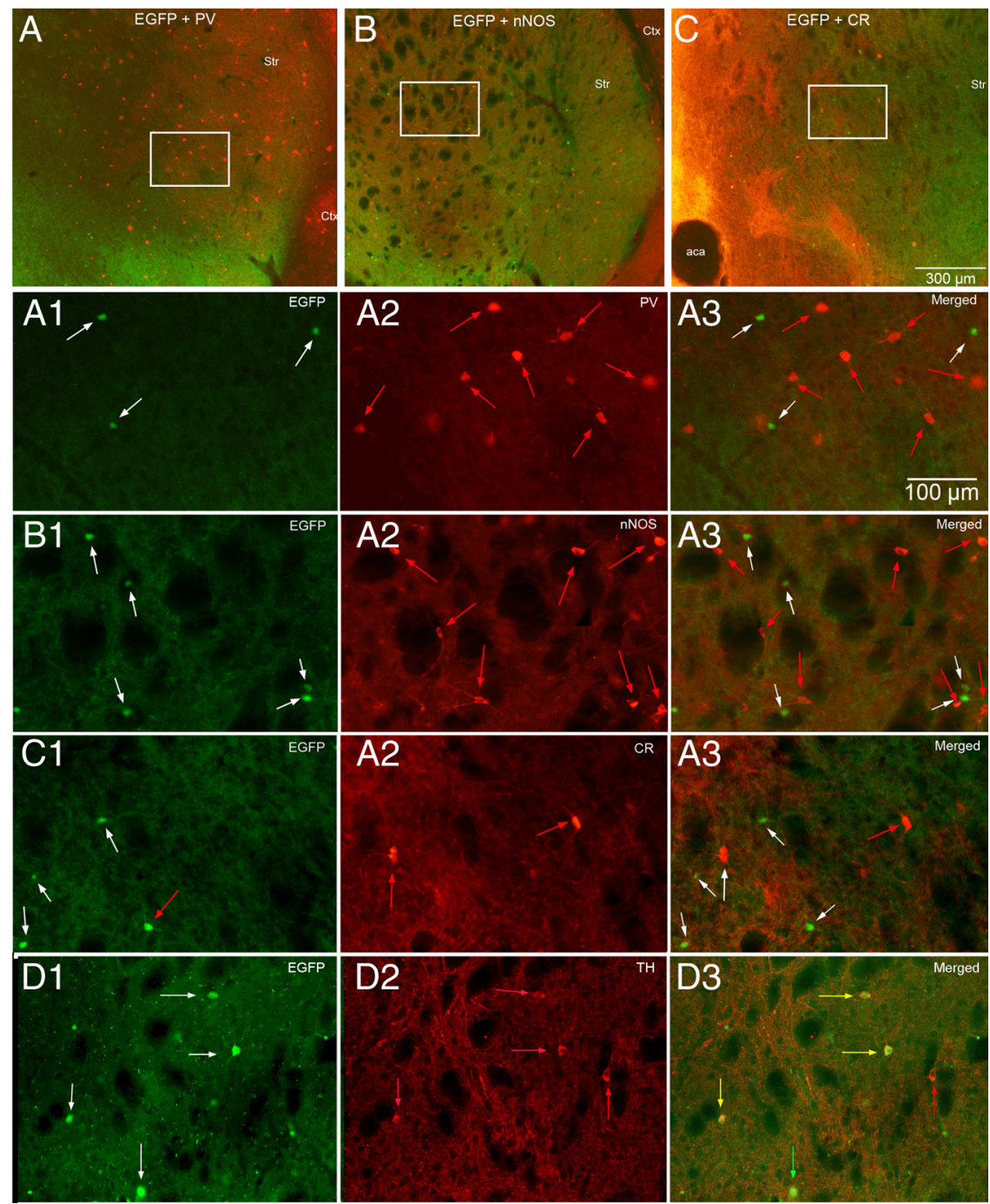

Figure 7. Neurochemical identification of striatal EGFP-TH ${ }^{+}$interneurons. A-C, Low-magnification double fluorescence mirographs of striatum showing EGFP-TH (green) simultaneously with PV immunofluorescence $(\boldsymbol{A})$, NOS immunofluorescence $(\boldsymbol{B})$, (EGFP-TH, PV, and merged), B1-B3 (EGFP-TH, NOS, and merged), and C1-C3 (EGFP-TH, CR, and merged). Note that 列 neurons (red arrows). D3, Merge of D1 and D2 showing neurons expressing both EGFP and TH (yellow arrows), EGFP but not TH (green arrow), and TH but not EGFP (red arrow). Str, Striatum; Ctx, cortex.

Additional increases in the amplitude of the injected current increased the maximum firing rate and accelerated the adaptation and accommodation and shortened the latency to the cessation of spiking.

However, when identical depolarizing current pulses were injected into neurons depolarized to $-73 \mathrm{mV}$ by constant current injection, Type III neurons exhibited a more linear $I-V$ relationship, exhibited a lowered threshold for spiking, and were capable of sustained spiking throughout the current pulse at a much higher firing rate than could be achieved with even larger current injections applied from rest. With higher intensity stimuli, firing was also blocked in these neurons, but the period of sustained firing was considerably lengthened compared with what was seen when stimuli were applied at the resting membrane potential. Strong depolarizing current pulses delivered to depolarized Type III neurons also elicited the expression of a plateau potential similar to that seen in Type I and Type II cells under appropriate 
conditions and, like those plateau potentials, was readily blocked by application of L-type $\mathrm{Ca}^{2+}$ channel antagonists (Fig. $4 D$, green arrow).

\section{Type IV neurons}

Type IV neurons were the second most abundant of the EGFP-TH ${ }^{+}$ neurons, comprising 21\% (29 of 139) of the striatal EGFP-TH ${ }^{+}$ neurons. Type IV neurons exhibited a linear $I-V$ relationship and an input resistance similar to that of Type II neurons $(471 \pm 30$ $\mathrm{M} \Omega$; range, 235-821 M $\Omega$ ). Type IV neurons exhibited a sag in response to hyperpolarizing current injections of similar time course and amplitude to that seen in Type I and II cells that could also be blocked by ZD7288 (Fig. 5B2), indicating that it was mediated by a similar $I_{\mathrm{h}}$. An example of a typical Type IV EGFP$\mathrm{TH}^{+}$neuron is illustrated in Figure 5.

The most characteristic feature of the Type IV neuron was the expression of a slow depolarization that closely resembled a lowthreshold spike, with a burst of fast sodium-potassium spikes riding on top (Fig. 5B1). All Type IV neurons exhibited this lowthreshold spike/burst, which could be elicited by a depolarizing current pulse delivered to the cell at rest $(-73 \mathrm{mV})$ as well as at the termination of a strong hyperpolarizing current injection.

Unlike Type I, II, and III neurons, which each exhibited an ensemble of electrophysiological properties unlike those of any cell type previously identified in striatum, the Type IV cell resembled in many ways the LTS interneuron described by Koós and Tepper (1999). That neuron and the Type IV EGFP-TH ${ }^{+}$neuron differed from the NPY/vasoactive intestinal peptide/SOM ${ }^{+}$ PLTS neuron described by Kawaguchi and colleagues (Kawaguchi, 1993; Kawaguchi et al., 1995) by the absence of plateau potentials riding on the response to depolarizing current injections, a slightly lower input resistance, and a significantly shorter duration action potential.

Means and SEMs of the electrophysiological properties of striatal EGFP-TH ${ }^{+}$neurons measured are reported in Table 1. ANOVA followed by Bonferroni's multiple comparisons and between the four cell types show that, consistent with our interpretation from the scatter plots, each of the EGFP-TH ${ }^{+}$cell types is statistically different from one or more of the other cell types in several different electrophysiological parameters.

\section{EGFP-TH ${ }^{+}$cell counting and retrograde labeling}

Retrograde labeling data and EGFP-TH ${ }^{+}$cell counts were obtained from six striatal hemispheres from three mice in which rhodamine beads were injected bilaterally into both the globus pallidus and substantia nigra. A total of $203 \mathrm{EGFP}-\mathrm{TH}^{+}$neurons were counted in the six hemispheres. The total number of EGFP$\mathrm{TH}^{+}$neurons in the mouse striatum was estimated using three different methods; optical fractionator, mean measured section thickness, and number weighted section thickness. All three methods generated similar numbers, but the number weighted section thickness approach consistently gave the smallest numbers and thus was the most conservative estimate. These are the numbers we report here.

The estimated number of EGFP- $\mathrm{TH}^{+}$neurons per striatum was $2684 \pm 1216(n=6)$ in which the mean Gundersen's coefficient of error was 0.12 . This is significantly greater than most estimates of the abundance of striatal neurons labeled by $\mathrm{TH}$ immunocytochemistry described in studies in the normal mouse or rat striatum (Tashiro et al., 1989b; Mao et al., 2001; Busceti et al., 2008). This may be attributable in part to several factors, including the increased sensitivity of the BAC transgenic approach as a result of incorporation of multiple copies of the EGFP
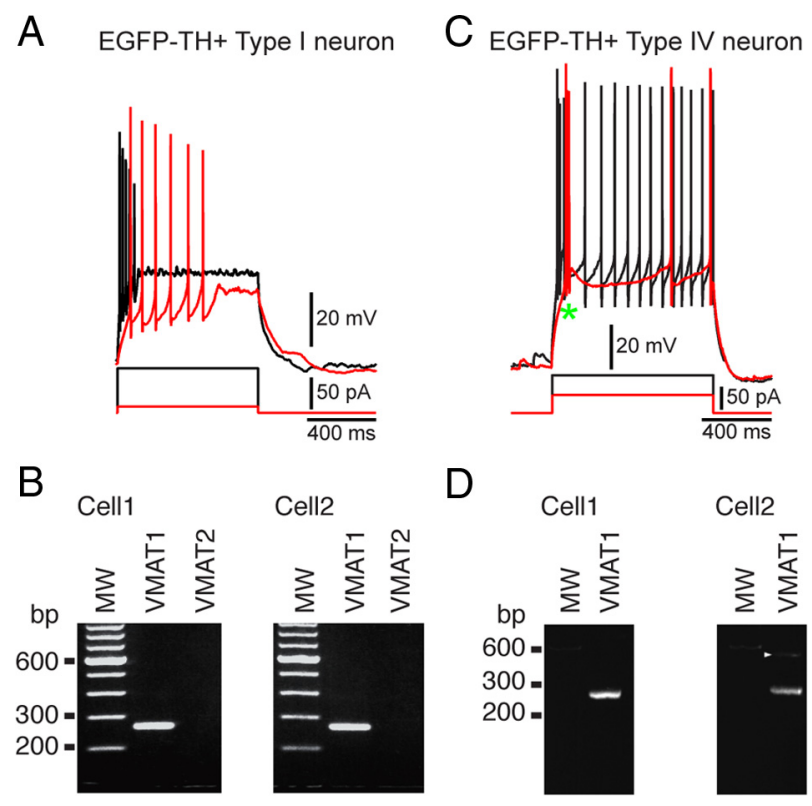

D

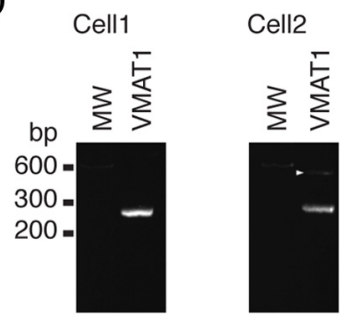

Figure 8. Results of single-cell RT-PCR performed on four EGFP-TH ${ }^{+}$neurons. $A$, Typical responses of a Type I neuron to depolarizing current injection. $\boldsymbol{B}$, Agarose gel from the cell shown in $A$ plus another Type I neuron showing that both express the amplicon for VMAT1 but not VMAT2. C, Typical responses of a Type IV neuron to depolarizing current injection. $\boldsymbol{D}$, Gels from the neuron shown in Cplus a second Type IV neuron show that Type IV neurons also express VMAT1. MW, Molecular weight.

gene (Gong et al., 2003), the relatively increased brightness of the striatal EGFP-TH ${ }^{+}$somata compared with either bright-field or dark-field immunocytochemical labeling, as well as other factors discussed below.

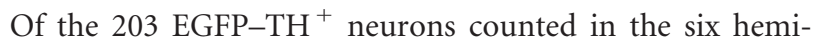
spheres, none were also labeled with rhodamine despite very dense retrograde labeling in the immediate areas of the EGFP$\mathrm{TH}^{+}$neurons (Fig. 6). The failure to find any retrogradely labeled EGFP-TH ${ }^{+}$neurons cannot, of course, completely rule out the possibility that a small fraction of these neurons does project to $\mathrm{SN}$ or GP, but it is clear that the vast majority of the striatal EGFP- $\mathrm{TH}^{+}$neurons cannot be striatonigral or striatopallidal SPNs and must therefore be interneurons.

\section{Immunocytochemical characterization of striatal EGFP-TH ${ }^{+}$neurons}

We tested striatal sections from EGFP- $\mathrm{TH}^{+}$mice for PV, NOS, or CR immunofluorescence to determine the extent of colocalization, if any, of these substances in striatal EGFP-TH ${ }^{+}$neurons. As shown in Figure 7, although numerous brightly fluorescent $\mathrm{PV}^{+}$, $\mathrm{NOS}^{+}$, and $\mathrm{CR}^{+}$neurons were observed, colocalization with EGFP was never observed. Thus, consistent with the electrophysiological data that showed physiological characteristics for each of the EGFP- $\mathrm{TH}^{+}$neurons clearly distinct from those reported previously for striatal fast-spiking or PLTS interneurons, the immunocytochemical data also show that the striatal EGFP-TH ${ }^{+}$ neurons are neurochemically distinct from previously described striatal interneurons.

Because the expression of the EGFP- $\mathrm{TH}^{+}$reporter is not a direct demonstration of the abundance of $\mathrm{TH}$ mRNA or $\mathrm{TH}$ protein but instead indicates rates of transcription of the $\mathrm{TH}$ gene (Gong et al., 2003), we performed TH immunostaining on striatal and midbrain sections from EGFP- $\mathrm{TH}^{+}$mice. To our surprise, although the majority of substantia nigra and ventral 
tegmental area EGFP-TH ${ }^{+}$neurons were also immunoreactive for TH (although a minority did not stain for $\mathrm{TH}$ and some TH-immunopositive neurons did not appear to express EGFP; data not shown), such double labeling of striatal neurons was almost nonexistent; in fact, very few striatal $\mathrm{TH}^{+}$neurons were found in control or transgenic mice even with high concentrations of primary antibody and long primary incubation times. We suspected that perhaps this was attributable to the striatal EGFP- $\mathrm{TH}^{+}$neurons expressing much lower levels of TH than midbrain dopaminergic neurons and/or efficient axonal transport of the enzyme to the terminals, similar to what was found to be the case in studies of GABA and GAD immunocytochemistry in certain striatal interneurons (Bolam et al., 1985; Kita and Kitai, 1988; Chesselet and Robbins, 1989). Therefore, we injected colchicine intrastriatally in three EGFP-TH ${ }^{+}$mice.

There was significant nonspecific damage in the injected striata so we analyzed the contralateral striata for $\mathrm{TH}^{+}$immunoreactivity and colocalization of $\mathrm{TH}$ and EGFP fluorescent labeling. In contrast to control striata, we found an abundant number of $\mathrm{TH}^{+}$immunofluorescent somata in the striata of colchicine-treated mice, similar to the number of EGFP$\mathrm{TH}^{+}$neurons observed in normal EGFP$\mathrm{TH}^{+}$transgenic mice. Figure 7 illustrates one representative section from the striatum of an EGFP-TH ${ }^{+}$mouse $3 \mathrm{~d}$ after colchicine injection. Thus, a majority of striatal EGFP-TH ${ }^{+}$neurons express $\mathrm{TH}$, albeit in much lower amounts than in the mesencephalic dopaminergic neurons.

\section{Single-cell RT-PCR phenotyping of striatal $\mathrm{TH}^{+}$neurons}

In $10 \mathrm{EGFP}^{-\mathrm{TH}^{+}}{ }^{+}$neurons that were recorded in whole-cell mode for short periods just long enough to identify the subtype of the EGFP- $\mathrm{TH}^{+}$neuron, the cytoplasm was aspirated and RTPCR was used to probe for the expression of VMAT1 and VMAT2. Although none of the neurons expressed amplicons for VMAT2, the transporter expressed by mesencephalic dopaminergic neurons, all 10 EGFP- $\mathrm{TH}^{+}$neurons exhibited robust expression of VMAT1 mRNA. Examples of gels from two Type I and two Type IV neurons, all of which showed expression of VMAT1 but not VMAT2, are shown in Figure 8.

\section{Synaptic connections of striatal EGFP- $\mathrm{TH}^{+}$interneurons}

Local electrical stimulation with single pulses evoked depolarizing synaptic potentials (DPSPs) in all striatal EGFP-TH ${ }^{+}$interneurons tested $(n=5)$. The DPSPs were composed of two components that reversed at different membrane potentials. The inhibitory component was an IPSP that exhibited a reversal potential at approximately $-65 \mathrm{mV}$ (Fig. $9 B)(64 \pm 1.5 \mathrm{mV} ; n=4)$ and could be blocked by bicuculline $(10 \mu \mathrm{M})$, indicating that it was mediated principally by $\mathrm{GABA}_{\mathrm{A}}$ receptors. Blockade of the
IPSP revealed a pure EPSP that was completely abolished by 10 $\mu \mathrm{M}$ DNQX, suggesting that it was mediated by non-NMDA receptors, consistent with the hyperpolarized membrane potentials and recording conditions, as shown for one representative Type I and II interneuron in Figure 9, B and C. Note that, in Figure 9, $B 3$ and $C 3$, combined application of bicuculline and CNQX totally abolished the synaptic responses, demonstrating that $10 \mu \mathrm{M}$ bicuculline resulted in a 100\% block of the IPSP and, similarly, 10 $\mu \mathrm{M}$ DNQX resulted in a $100 \%$ block of the EPSP.

Striatal Type I EGFP- $\mathrm{TH}^{+}$interneurons also responded to stimulation of the cortex with DPSPs (Fig. 9D). Unlike the responses to local stimulation, bicuculline had no effect on the cortically evoked DPSPs, indicating that they were pure EPSPs. As with local stimulation, bath application of $10 \mu \mathrm{M}$ DNQX completely abolished the EPSP, indicating that it was mediated predominantly or exclusively by non-NMDA receptors.

Like Type I interneurons, Type II interneurons were well integrated into the synaptic network of the striatum. Local stimulation elicited EPSPs and IPSPs blocked by DNQX and bicuculline, just like in the Type I interneurons (Fig. 9C). 

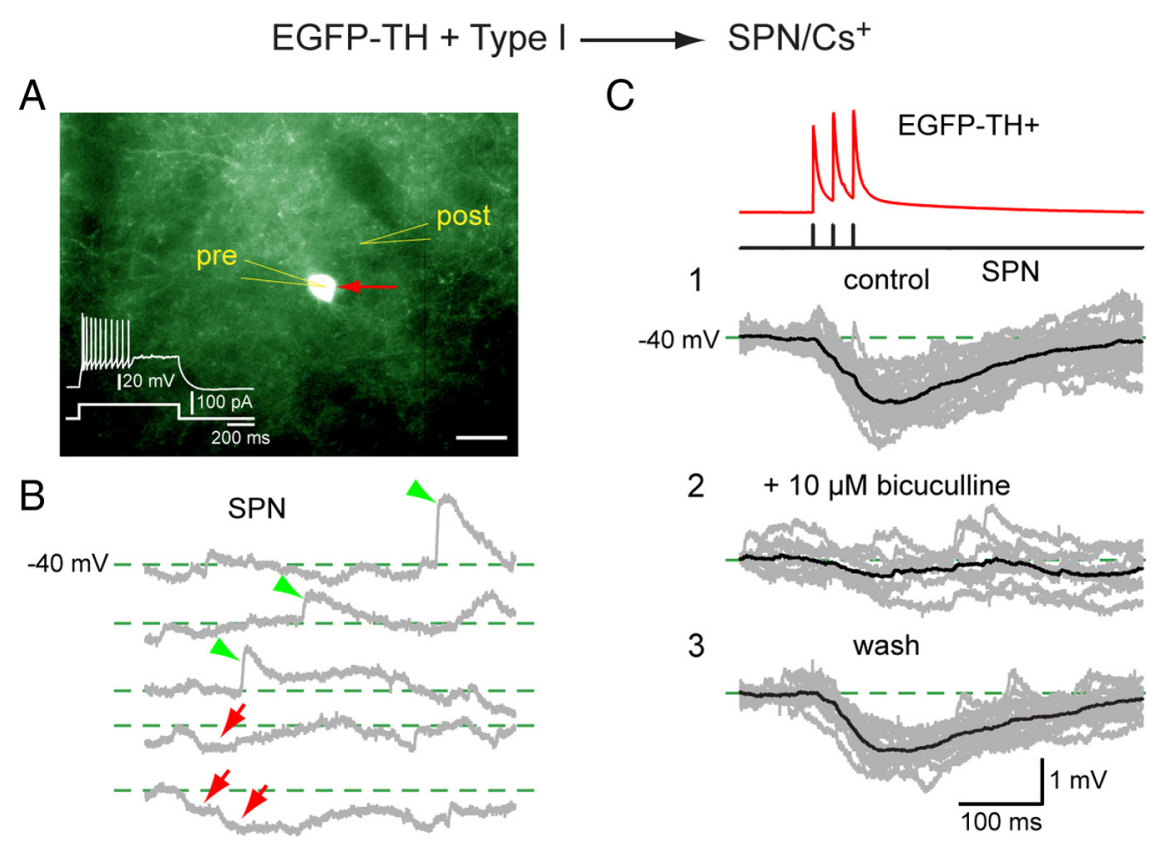

Figure 10. Paired whole-cell current-clamp recording between a presynaptic Type I neuron and a postsynaptic SPN. Both neurons were recorded with a $\mathrm{CSMeSO}_{4}$ internal solution. $\boldsymbol{A}$, The Type I neuron (red arrow, pre) is fluorescent and shows a typical response to depolarizing current (inset). The postsynaptic SPN (post) is not fluorescent and cannot be seen under epifluorescence illumination. Scale bar, $20 \mu \mathrm{m}$. B, Depolarizing the SPN to $-40 \mathrm{mV}$ reveals both spontaneous EPSPs (green arrowheads) and IPSPs (red arrows). C1, Current pulses in the Type I neuron elicit three spikes that evoke three hyperpolarizing IPSPs in the SPN at -40 $\mathrm{mV}$ that summate to $>1 \mathrm{mV}$. C2, The IPSP was reversibly blocked by bicuculline (10 $\mu \mathrm{m})$ and recovered after wash (C3), showing that the synaptic response was mediated by a $\mathrm{GABA}_{\mathrm{A}}$ receptor.

We also obtained a limited number of recordings between synaptically connected pairs of striatal EGFP-TH ${ }^{+}$interneurons and spiny neurons. Of a total of 36 pairs of neurons between 20 and $60 \mu \mathrm{m}$ apart, 54 possible synaptic connections were tested (i.e., in 18 of 36 pairs, synaptic connections were tested in both directions). Synaptic connectivity was found in 11 pairs, corresponding to an overall connectivity probability (in either direction) of $20.3 \%$. None of these connections was reciprocal. Within the 11 connected pairs, five presynaptic neurons were EGFP$\mathrm{TH}^{+}$, three Type I, one Type II, and one Type III, giving an EGFP-TH ${ }^{+}>$SPN connectivity of $\sim 14 \%$ ( 5 of 36). Surprisingly, we also found six synaptically connected pairs in which the presynaptic neuron was an SPN of $18 \mathrm{SPN}>\mathrm{EGFP}_{-} \mathrm{TH}^{+}$pairs, giving a connectivity of $33 \%$ ( 6 of 18). In all six of these cases, the postsynaptic neuron was a Type I interneuron. To our knowledge, these are the first examples of electrophysiologically verified monosynaptic connections between a presynaptic SPN and any type of striatal GABAergic interneuron. The responses of an SPN to a three-spike burst in a Type I neuron evoked by a train of three short depolarizing current pulses are shown in Figure 10C. The monosynaptic IPSP exhibited an amplitude of $0.7 \pm 0.04 \mathrm{mV}$ with the SPN held at $-40 \mathrm{mV}$. The IPSP was completely and reversibly blocked by $10 \mu \mathrm{M}$ bicuculline, showing that it was $\mathrm{GABA}_{\mathrm{A}}$ mediated. The synaptic connection was extremely reliable: no failures were observed during the entire recording period.

We also recorded monosynaptic IPSCs in a SPN in response to single action potentials or trains evoked by current injection into Type II or Type III interneurons, as shown in Figure 11. Single presynaptic action potentials elicited a small inward current of $10 \pm 2 \mathrm{pA}$ in an SPN held at $-70 \mathrm{mV}$ recorded with a $\mathrm{CsMeSO}_{4}$ internal solution (Fig. 10C). The Type II-SPN synapse was less reliable than the Type I-SPN synapse, exhibiting a failure rate of
59\%. Longer depolarizing pulses delivered to the presynaptic interneuron evoked a sustained high-frequency discharge in Type II neurons that resulted in multiple synaptic responses that summated quite effectively to produce a sustained inward current of 25-30 pA. That the synapse exhibits both short-term facilitation and short-term depression is clearly illustrated in Figure $10 \mathrm{~B}$. The inward synaptic currents were completely and reversibly abolished by bath application of $10 \mu \mathrm{M}$ bicuculline, indicating that, like the postsynaptic responses of SPNs to Type I inputs, the synaptic response to spiking in Type II neurons consists of a $\mathrm{GABA}_{\mathrm{A}}$ IPSC (Fig. $11 \mathrm{D}$ ).

Single presynaptic spikes evoked in a Type III interneuron elicited IPSCs of similar amplitude $(21 \pm 2 \mathrm{pA})$ as those elicited from Type II neurons amplitude at the resting membrane potential (Fig. $10 G)$. However, the recordings in Figure $10 G$ were obtained with a normal postsynaptic internal solution (no $\mathrm{Cs}^{2+}$ and low $\mathrm{Cl}^{-}$) and thus represent significantly larger and more powerful postsynaptic responses. In addition, the IPSC was extremely reliable and did not exhibit any failures during the period of recording that consisted of $>100$ trials. Furthermore, under current clamp, paired-pulse stimulation of the Type III neuron elicited IPSPs in the postsynaptic SPN depolarized to threshold $(0.67 \pm 0.05 \mathrm{mV})$. These IPSPs were sufficient to delay the onset of spiking by 55.1 $\mathrm{ms}$, corresponding to a $23 \%$ reduction in the evoked firing rate, indicating that inputs from single Type III neurons can powerfully modulate the firing activity of SPNs (Fig. 10E,F).

Of our sample of 11 synaptically connected pairs of EGFP$\mathrm{TH}^{+}$interneurons and SPNs, six of the presynaptic neurons proved to be an SPN. In all six cases, the postsynaptic neuron was a Type I. In five of these paired recordings of synaptically connected neurons, both presynaptic and postsynaptic neurons were recorded with normal internal solution. Current pulses injected into the SPN elicited a single action potential or train of presynaptic spikes that evoked IPSPs in Type I neurons that were sufficient to slow or completely block the subsequent action potential in postsynaptic Type I neuron that were depolarized to threshold, as shown in Figure 12. In these five pairs, single spikes in the SPN elicited IPSPs in the postsynaptic Type I neuron, ranging from 0.18 to $2.3 \mathrm{mV}$ (mean IPSP amplitude, $0.98 \pm 0.3 \mathrm{mV}$; latency, $1.2 \pm 0.1 \mathrm{~ms} ; p=0.37 ; n=3$ ).

A quantitative summary of all the paired recording experiments, listing the number of different combinations of presynaptic and postsynaptic neurons tested, the synaptic response probabilities, the mean amplitudes of the IPSPs/IPSCs, the percentage block by $10 \mu \mathrm{M}$ bicuculline, and their onset latency, is shown in Table 2.

\section{Morphology of striatal $\mathrm{TH}^{+}$neurons}

Thirty-four biocytin-filled EGFP-TH ${ }^{+}$neurons were recovered in suitable condition for quantitative morphological analysis. Neurons were reconstructed with a drawing tube and superimposed on a grid of concentric circles to analyze characteristics of 


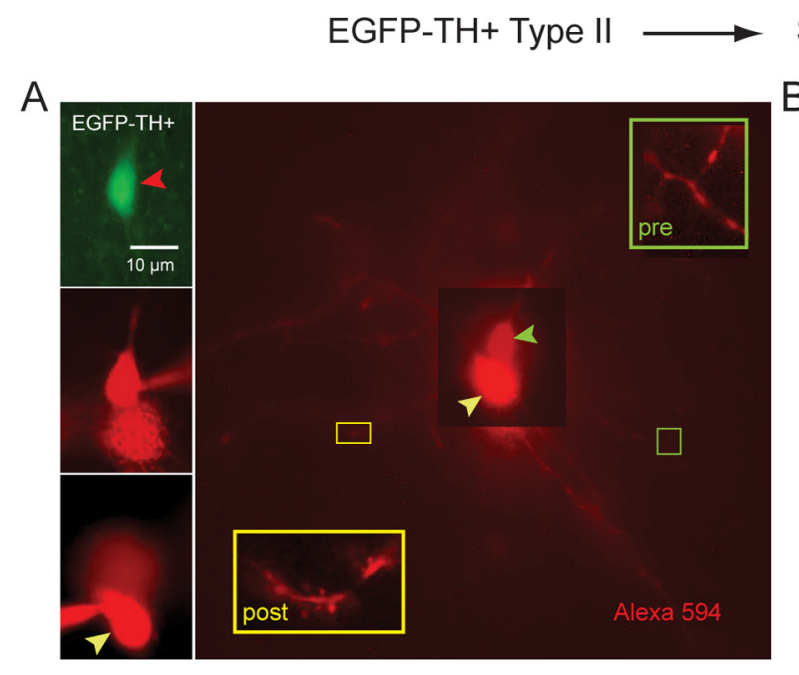

\section{SPN}

B
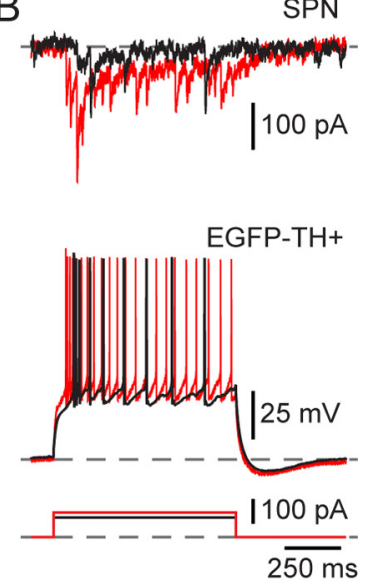

C

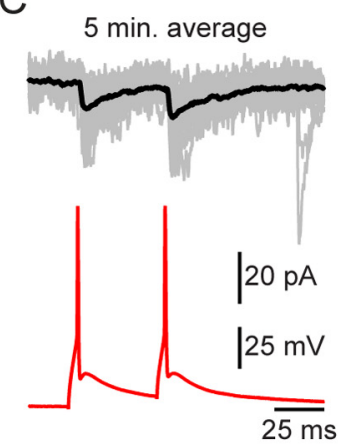

$\mathrm{D}$
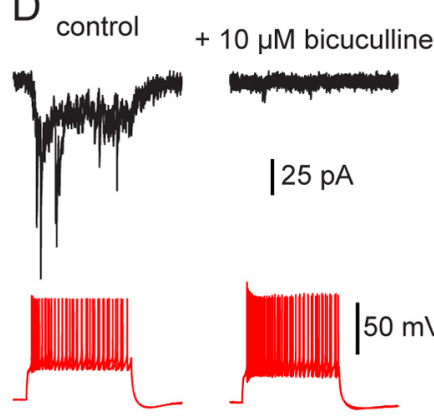

$10 \mu \mathrm{M}$ bicuculline

wash
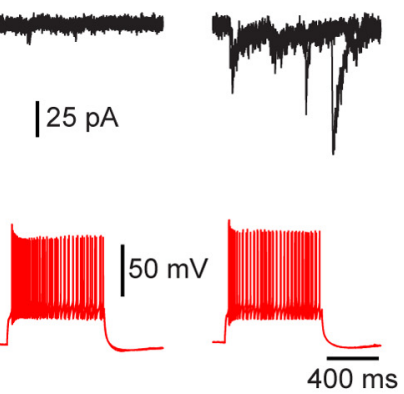

EGFP-TH+ Type III $\longrightarrow$ SPN

$\mathrm{E}$

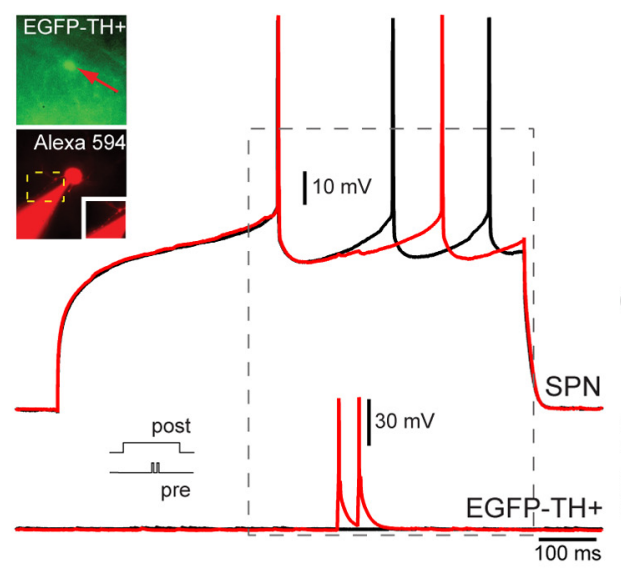

$\mathrm{F}$
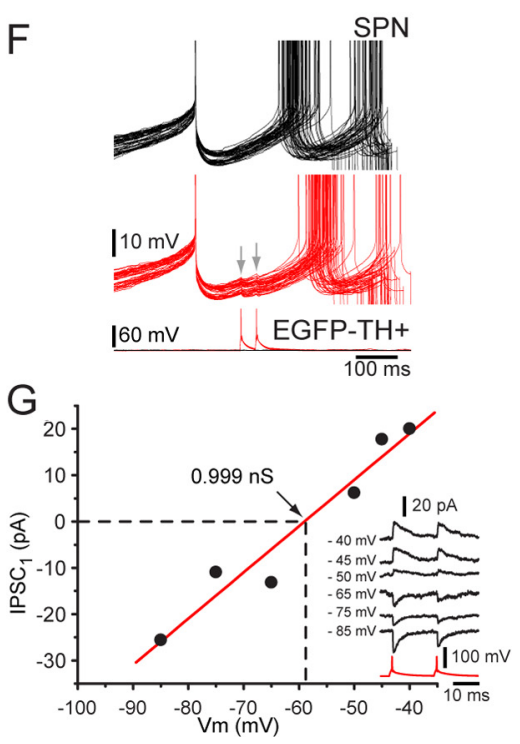

Figure 11. Spiking in Type II and Type III neurons elicits IPSCs in SPNs and delays firing in response to current injection. $A$, Connected pair consisting of a presynaptic EFGP ${ }^{+}$Type II neuron (top left) and a postsynaptic SPN (bottom left). The insets are high-magnification micrographs showing an aspiny Type II (pre) dendrite and a spiny SPN dendrite (post) after both were patched in whole-cell mode and stained with Alexa 594. B, Top, Current pulses injected into the Type II neuron elicited a train of presynaptic spikes that evoked IPSCs in the postsynaptic SPN. Both short-term depression and early facilitation were evident. C, Two spikes evoked by two $5 \mathrm{~ms}$ pulses $50 \mathrm{~ms}$ apart in the Type II neuron result in modest paired-pulse facilitation in the same SPN. Black traces are averages, and gray traces are individual trials. D, The IPSCs were reversibly blocked by bicuculline (10 $\mu \mathrm{M}$ ) showing that they were mediated by a $G A B A_{A}$ receptor. $E$, Connected pair consisting of a presynaptic Type III neuron and a postsynaptic SPN (inset) Two presynaptic spikes separated by $50 \mathrm{~ms}$ (bottom trace) delay the occurrence of depolarization induced spiking in the postsynaptic SPN (top black trace) by almost $100 \mathrm{~ms}$ (top red trace). $\boldsymbol{F}$, Entire dataset from which the traces in $\boldsymbol{E}$ were selected. Depolarization evoked spiking in SPN under control conditions (black traces) and in the presence of two spikes in the presynaptic neuron the dendritic and axonal arborizations (Sholl, 1953). Examples of the reconstructed neurons and the resulting Sholl plots are shown in Figure 13. Because there were no significant morphometric differences among the four cell types in the quantitative measurements, the measurements from all 34 neurons were pooled and are presented in Table 3.

Striatal EGFP- $\mathrm{TH}^{+}$interneurons were medium sized, with the long axis of the soma ranging from 11.4 to $24 \mu \mathrm{m}$ and its perpendicular ranging from 7.1 to 13.2 $\mu \mathrm{m}$. ANOVA followed by Bonferroni's post hoc tests revealed that none of the cell types differed from any of the other cell types in terms of somatic area, perimeter, length of long or short axes, or number of primary dendrites.

Somata were most frequently round or ovoid ( 28 of $34 ; 77 \%$ ). The remaining six $(23 \%)$, all of which were Type I interneurons, were pyramidal shaped. The dendrites of most of the EGFP-TH ${ }^{+}$interneurons of all four subtypes were mostly or completely aspiny and varicose (30 of $34 ; 88 \%$ ). The degree of dendritic varicosity varied from slight, as illustrated for a Type II neuron in Figure $13 B$, to considerable, as illustrated by the Type IV neuron in Figure 13D.

Four of the stained neurons appeared markedly different from the rest. All of these cells were Type I interneurons. The dendrites of these cells exhibited fairly dense, thick stick-like appendages that appeared to lack distinct spine heads. Nevertheless, these neurons were clearly not SPNs (Fig. $12 \mathrm{~A}, \mathrm{C})$. Low- and high-magnification micrographs of a biocytin-filled spiny Type I EGFP-TH ${ }^{+}$interneuron are shown in Figure 14 along with a representative biocytin-filled SPN, also from the striatum of an EGFP-TH ${ }^{+}$mouse. Several differences between the two neuronal types are readily apparent. The Type I neuron is slightly larger than the SPN, and the density of spines covering the dendrites of the SPN is an order of magnitude greater than that of the Type I neuron. High-magnification inspection of dendrites of the two neuronal types reveals that, compared with the spines on the SPN neuron, the dendritic specializations on the Type I neuron often seem to lack a spine head, and many are longer than the spines on the SPNs.

(red traces). Note the reliability of this connection. G, I-V plot for this synaptic response showing a reversal potential consistent with mediation by $\mathrm{Cl}^{-}$ions and a synaptic conductance near $1 \mathrm{nS}$. 


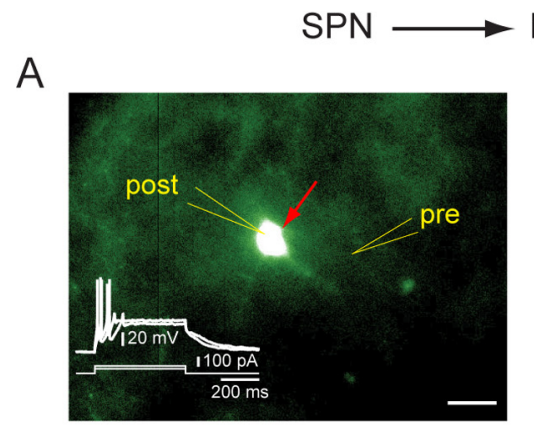

B

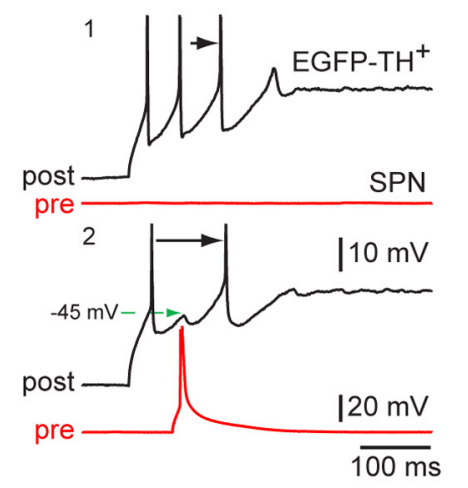

EGFP-TH ${ }^{+}$Typel / $\mathrm{Cs}^{+}$

C
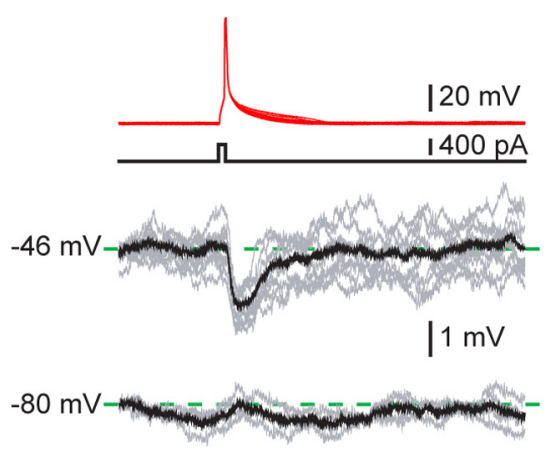

$10 \mu \mathrm{M}$ bicuculline

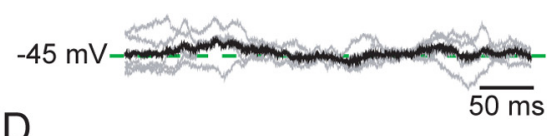

- IPSP from SPN $\rightarrow$ EGFP- $\mathrm{TH}^{+}$

- spontaneous IPSP

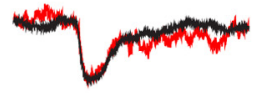

\section{SPN $\longrightarrow$ EGFP-TH ${ }^{+}$Typel / normal chloride}

E

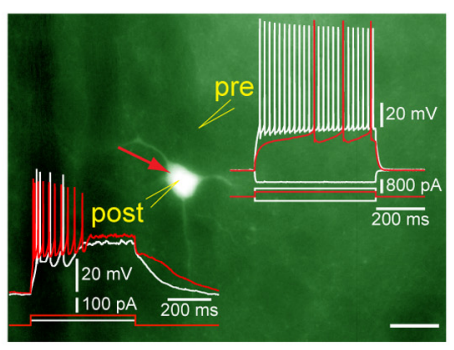

$\mathrm{F}$

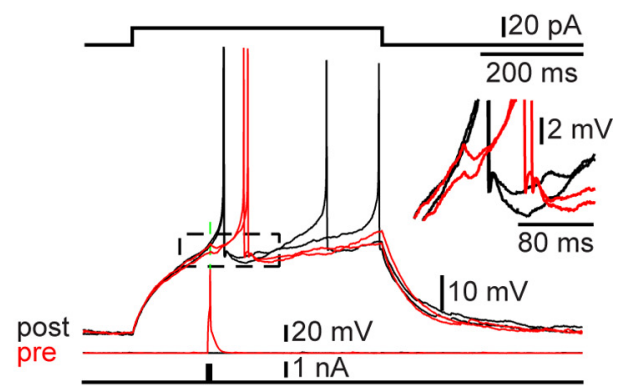

G

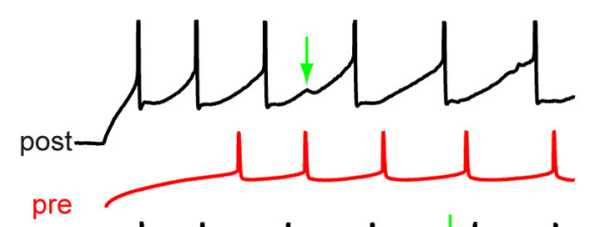

$\mathrm{H} \quad 1$

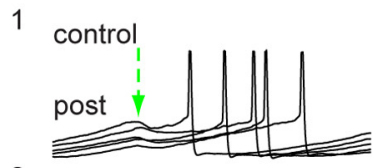

2

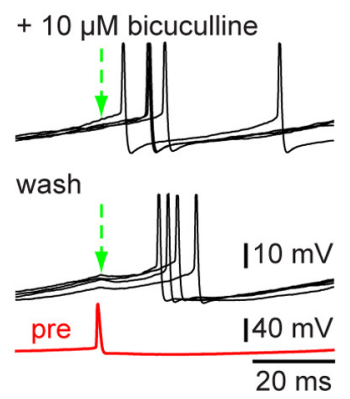

Figure 12. Whole-cell recordings of two connected pairs in which the presynaptic neuron was an SPN and the postsynaptic neuron was a Type I neuron. $\boldsymbol{A}-\boldsymbol{D}$, Presynaptic and postsynaptic neurons recorded with $140 \mathrm{~mm} \mathrm{CsMeSO}_{4}$ internal solution. $\boldsymbol{A}$, Postsynaptic EGFP-TH ${ }^{+}$Type I neuron (red arrow, post) is fluorescent and shows typical response to depolarizing current pulses. Presynaptic SPN are not fluorescent and cannot be seen (pre) and were patched under DIC visualization. B1, Depolarizing current pulse evokes three spikes in a Type I neuron (top black trace). $\boldsymbol{B}$ 2, Single action potential elicited in the SPN (red trace) causes an IPSP $(-45 \mathrm{mV})$ in the Type I neuron held at $-48 \mathrm{mV}$ (black trace) that was sufficient to completely block the second of three spikes evoked in the Type I neuron. Mean IPSP amplitude, $0.58 \pm 0.14 \mathrm{mV}$; latency, $2.6 \pm 0.13 \mathrm{~ms} ; p=100 \%$. C, Single spike (top red trace) in the SPN evokes a hyperpolarizing IPSP in a Type I neuron held at $-46 \mathrm{mV}$. Black trace is average, and gray traces are individual trials. Note that the IPSP failure rate is zero. The IPSP is reversed at $-80 \mathrm{mV}$ (middle) and is completely blocked by $10 \mu \mathrm{m}$

The axonal arborization of the spiny Type I neurons is also qualitatively different from that of the local SPNs. This is also illustrated in Figure 14. Whereas the local collaterals of SPNs are by and large smooth, with intermittently spaced varicose segments, the axonal arborization of the Type I EGFP- $\mathrm{TH}^{+}$interneuron consists of a dense plexus of highly branched thin processes, heavily beaded with large $(>1 \mu \mathrm{m})$, round varicosities, most of which are en passant.

It was not possible to discriminate among the aspiny Type II, III, and IV interneurons in our sample based on qualitative or quantitative morphological criteria. For all subtypes, the axon emerged from the soma or a proximal dendrite and branched almost immediately, forming a dense local axon collateral plexus that occupied a volume coextensive with and sometimes extending beyond the dendritic tree of the issuing neuron. The collaterals were highly branched and studded with large numbers of varicosities. None of the filled cells exhibited a single axonal branch that was larger than the rest or that could be clearly identified as the main axon, and in none of the cells was there evidence of a single long axon that projected away from the immediate locale of the parent cell, consistent with the retrograde labeling data that identified them as interneurons.

\section{Discussion}

There are four distinct subtypes of EGFP-TH ${ }^{+}$neurons in mouse striatum Striatal EGFP-TH ${ }^{+}$neurons could be reliably divided into four subtypes based on a number of electrophysiological charac-

$\leftarrow$

bicuculline (bottom), indicating a GABA $\mathrm{APSP}$. D, Comparison of a spontaneous IPSP and one evoked from the SPN shows them to have identical amplitudes and time courses, suggesting that some of the spontaneous IPSPs in Type I neurons arise from surrounding SPNs. E-G, Another connected pair in which the presynaptic neuron was an SPN and the postsynaptic neuron was a Type I. Both presynaptic and postsynaptic neurons recorded with normal internal solution. E, Postsynaptic Type I neuron (red arrow, post) is fluorescent. Presynaptic SPN is not fluorescent and cannot be seen (pre) and was patched under DIC visualization. $\boldsymbol{F}$, Train of spikes in the presynaptic SPN elicited by a current pulse (red traces) elicit IPSPs (green arrows) in the postsynaptic Type I neuron (black traces). The IPSPs delay the onset of the subsequent spike. $\mathbf{G}$, Single depolarizationevoked spikes in the SPN elicit IPSPs that delay the occurrence of the subsequent spike in the postsynaptic Type I neuron depolarized to threshold by current injection. $\mathbf{H 2}$, Bicuculline at $10 \mu \mathrm{m}$ blocks the IPSPs and the subsequent postsynaptic spikes occur with a decreased latency. $\boldsymbol{H 3}_{\mathbf{3}}$, The IPSP returns after washout, and the latency to the subsequent postsynaptic spike increases. Scale bars: $A, E, 20 \mu \mathrm{m}$. 
Table 2. Summary of pairs recording of striatal EGFP-TH ${ }^{+}$interneurons in adult mice

\begin{tabular}{|c|c|c|c|c|c|c|c|}
\hline$n$ (pairs) & $\begin{array}{l}\text { Synaptic } \\
\text { connections }\end{array}$ & $\begin{array}{l}\% \text { of pairs } \\
\text { recorded }\end{array}$ & $\begin{array}{l}\text { Synapse } \\
\text { type }\end{array}$ & $\begin{array}{l}p(\%) \text { connections and } \\
\text { recording condition }\end{array}$ & $\begin{array}{l}\text { Amplitude of } \\
\text { connection }(\mathrm{mV} / \mathrm{pA})\end{array}$ & $\begin{array}{l}\text { Inhibition by } \\
\text { bicuculline (\%) }\end{array}$ & $\begin{array}{l}\text { Onset } \\
\text { latency (ms) }\end{array}$ \\
\hline 32 & 3 & 9.4 & Type I to SPN & $\begin{array}{l}\text { (1) } p=100 \%\left(\mathrm{Cs}^{+}\right) \\
\text {(2) } p=17 \%\left(\mathrm{Cl}^{-}\right)\end{array}$ & $\begin{array}{r}0.7 \pm 0.04 \mathrm{mV} \text { at }-40 \mathrm{mV} \\
9 \pm 2 \mathrm{pA} \text { at } \mathrm{HP}=50 \mathrm{mV}\end{array}$ & 82 & $\begin{array}{l}1.6 \pm 0.1 \\
1.1 \pm 0.3\end{array}$ \\
\hline 2 & 1 & 50 & Type II to SPN & $p=41.6 \%\left(\mathrm{Cs}^{+}\right)$ & $10 \pm 2 \mathrm{pA}$ at $\mathrm{HP}=-70 \mathrm{mV}$ & 100 & $1.2 \pm 0.07$ \\
\hline 2 & 1 & 50 & Type III to SPN & $p=100 \%\left(\mathrm{Cl}^{-}\right)$ & $21 \pm 2 \mathrm{pA}$ at $\mathrm{HP}=-70 \mathrm{mV}$ & & $0.6 \pm 0.04$ \\
\hline 18 & 6 & 33.3 & SPN to Type I & $\begin{array}{l}\text { (1) } p=100 \%\left(\mathrm{Cs}^{+}\right) \\
\text {(5) } p=37 \pm 8 \%\left(\mathrm{Cl}^{-}\right)\end{array}$ & $\begin{array}{l}1.8 \pm 0.11 \mathrm{mV} \text { at }-44 \mathrm{mV} \\
0.98 \pm 0.3 \mathrm{mV} \text { at }-45 \mathrm{mV}\end{array}$ & $\begin{array}{l}100 \\
100\end{array}$ & $\begin{array}{l}1.6 \pm 0.13 \\
1.2 \pm 0.1\end{array}$ \\
\hline
\end{tabular}

Summary of paired recording experiments. "Synaptic connections" refers to the number of connections observed in the direction specified by "Synapse type." p refers to the probability that a spike in the presynaptic neuron resulted in an IPSP/IPSC in the postsynaptic neuron. Numbers in parentheses refer to the $n$ of connections that each $p$ value is based on. "Onset latency" refers to delay between the peak of the presynaptic spike and the onset of the IPSC. HP, Hyperpolarization.

teristics. The majority of the cells were Type I, and Type I and Type IV cells together accounted for $\sim 80 \%$ of all the striatal EGFP-TH ${ }^{+}$neurons.

With the exception of the Type IV neuron, which resembled the LTS GABAergic interneuron described by Koós and Tepper (1999) in several respects, each of the other EGFP-TH ${ }^{+}$cell types displayed an electrophysiological profile that was different from that described previously for any striatal cell type (Tepper and Bolam, 2004). Types II and IV, capable of sustained firing over $200 \mathrm{~Hz}$, are clearly subtypes of fast-spiking neuron, but none of these neurons expressed PV (or CR or NOS). Thus, there are (at least) two additional types of fast-spiking neuron in striatum other than the well known $\mathrm{PV}^{+}$FSI.

\section{Striatal EGFP- $\mathrm{TH}^{+}$neurons are \\ GABAergic interneurons}

Identification of striatal $\mathrm{TH}^{+}$neurons as interneurons or projection neurons has been controversial, with some authors arguing that these cells are interneurons (Dubach et al., 1987; Betarbet et al., 1997; Cossette et al., 2005; Mazloom and Smith, 2006; Huot and Parent, 2007), whereas others have argued that they are SPNs (Tashiro et al., 1989a,b; Darmopil et al., 2008). Our retrograde tracing experiments failed to label any EGFP-TH ${ }^{+}$neurons. Furthermore, none of the biocytin-labeled EGFP-TH ${ }^{+}$ neurons exhibited the distinctive electrophysiological or morphological profiles of SPNs. Thus, our conclusions are consistent with that showing that the overwhelming majority of striatal EGFP-TH ${ }^{+}$ neurons are interneurons.

Data from synaptically connected pairs of EGFP-TH ${ }^{+}$interneurons and SPNs showed that spikes in EGFP-TH ${ }^{+}$interneurons resulted in $\mathrm{GABA}_{\mathrm{A}}$ IPSPs/IPSCs in SPNs, consistent with previous studies that showed that striatal $\mathrm{TH}^{+}$neurons also express GAD (Betarbet et al., 1997; Mura et al., 2000; Cossette et al., 2005; Mazloom and Smith, 2006; Tandé et al., 2006; Huot and Parent, 2007). Thus, striatal EGFP-TH ${ }^{+}$interneu-

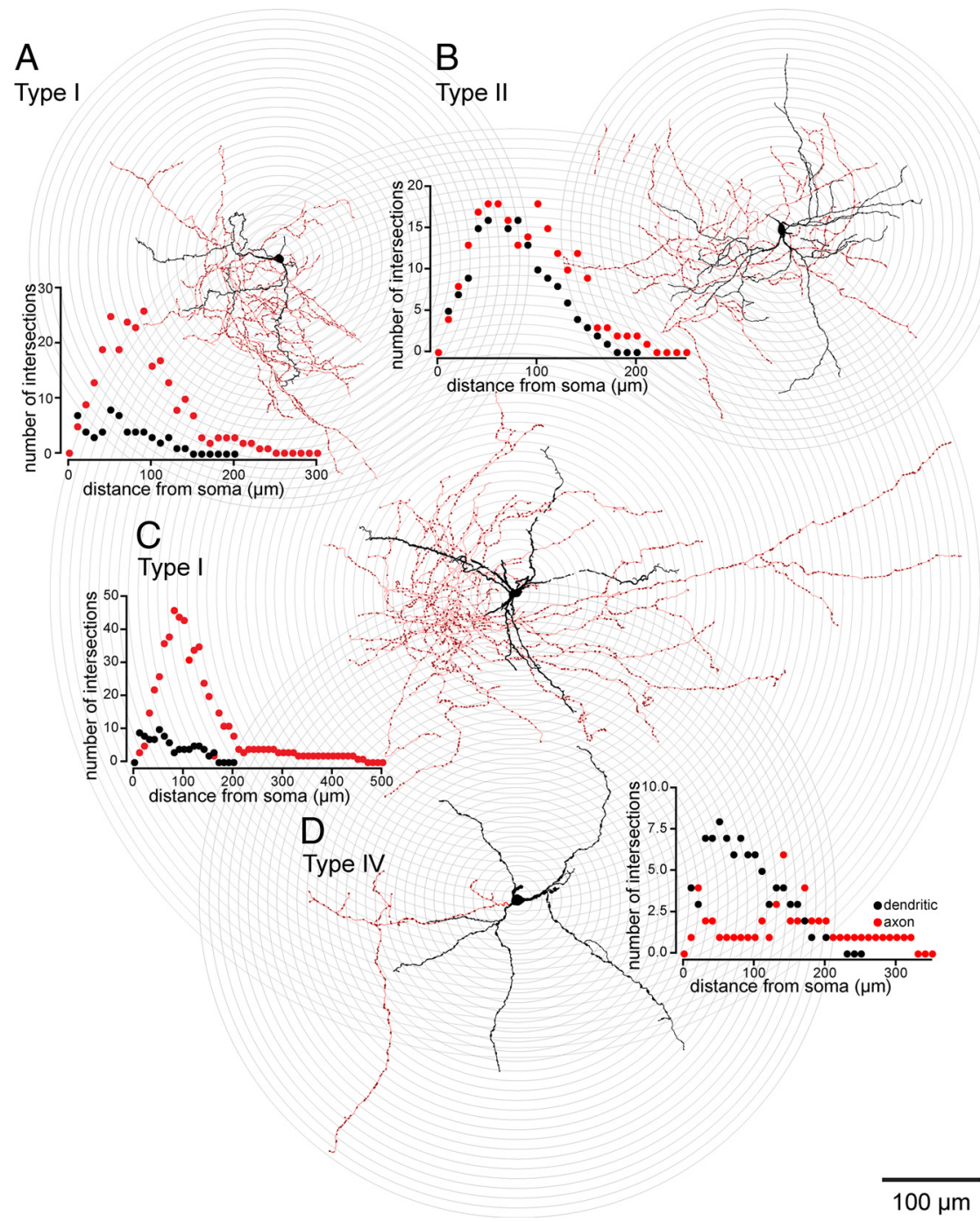

Figure 13. Drawing tube reconstructions of EGFP-TH ${ }^{+}$neurons filled with biocytin after recording, superimposed on concentric circles for Sholl analyses. Striatal EGFP-TH ${ }^{+}$neurons had three to five primary dendrites that branched between 15 and $50 \mu \mathrm{m}$ from the soma and gave rise to a modest arborization of secondary and tertiary varicose dendrites. Dendrites are plotted in black and axons in red in the Sholl plots. The quantitative morphometric results are given in Table 3. All Type II-IV EGFP-TH ${ }^{+}$neurons were aspiny, but 6 of 26 Type Ineurons expressed sparse spine-like processes on their higher-order dendrites (e.g., $A$ and $\boldsymbol{C}$; see Fig. 14). The axonal arborizations were sometimes quite dense $(A-C)$, reaching a maximum density between 50 and $120 \mu \mathrm{m}$ from the soma (red circles in Sholl plots) and were studded throughout with small varicosities (A-D; deep red dots on the axons), presumably synaptic boutons. In these reconstructions, the soma and dendrites are shown in black, and the axon are shown in red and varicosities in dark red.

rons represent four novel subtypes of striatal GABAergic interneurons.

Single-cell RT-PCR on 10 EGFP-TH ${ }^{+}$interneurons revealed that all expressed VMAT1, normally associated with large dense 
Table 3. Anatomical parameters of striatal EGFP-TH ${ }^{+}$interneurons in adult mice

\begin{tabular}{|c|c|c|c|c|c|c|c|c|c|c|c|}
\hline & \multirow{3}{*}{$\begin{array}{l}\text { Somatic area } \\
\left(\mu \mathrm{m}^{2}\right)\end{array}$} & \multirow{3}{*}{$\begin{array}{l}\text { Perimeter } \\
(\mu \mathrm{m})\end{array}$} & & & \multirow{3}{*}{$\begin{array}{l}\text { Number of } \\
\text { primary } \\
\text { dendrites }\end{array}$} & \multirow{2}{*}{\multicolumn{3}{|c|}{ Processes on dendrites }} & \multicolumn{3}{|l|}{ Sholl analysis } \\
\hline & & & \multicolumn{2}{|c|}{ Soma size ( $\mu \mathrm{m})$} & & & & & \multirow{2}{*}{$\begin{array}{l}\text { Number of dendritic } \\
\text { tips }\end{array}$} & \multirow{2}{*}{$\begin{array}{l}\text { Mean dendritic field } \\
\text { diameter }(\mu \mathrm{m})\end{array}$} & \multirow{2}{*}{$\begin{array}{l}\text { Mean axonal field } \\
\text { diameter ( } \mu \mathrm{m})\end{array}$} \\
\hline & & & Width & Height & & Varicose & Spine & Both & & & \\
\hline$n=34$ & $\begin{array}{r}112.7 \pm 7.6 \\
(65-266)\end{array}$ & $\begin{array}{r}37.7 \pm 1.5 \\
(27-60)\end{array}$ & $\begin{array}{c}15.2 \pm 0.6 \\
(9-24)\end{array}$ & $\begin{array}{c}10.8 \pm 0.4 \\
(7-18)\end{array}$ & $\begin{array}{c}3.3 \pm 0.1 \\
(2-4)\end{array}$ & 28 of 34 & 4 of $34^{a}$ & 2 of 34 & $\begin{aligned} 16.2 & \pm 1.9(5-32) \\
n & =17\end{aligned}$ & $\begin{array}{c}173 \pm 10(140-220) \\
n=7\end{array}$ & $\begin{array}{c}267 \pm 38(170-460) \\
n=7\end{array}$ \\
\hline
\end{tabular}

Mean morphometric parameters from all EGFP-TH ${ }^{+}$neurons intracellularly labeled with biocytin after recording. All values are given as mean \pm SEM.

${ }^{a}$ All four spiny neurons were Type $\mathrm{I}$.

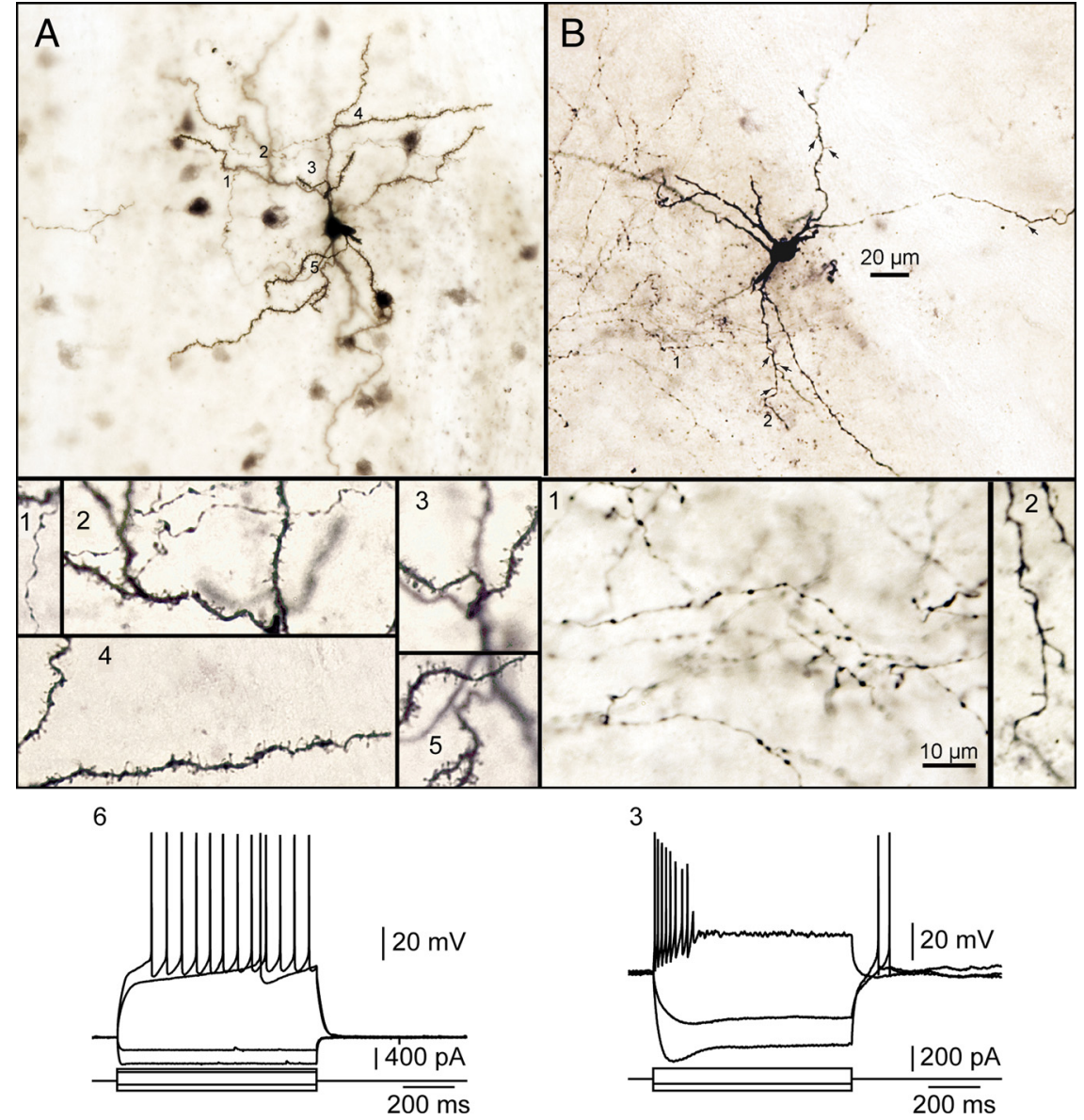

Figure 14. Characteristic anatomy of a typical SPN and a spiny EGFP-TH ${ }^{+}$Type I neuron filled with biocytin after whole-cell recording from adult mouse slices. $\boldsymbol{A}$, Low-magnification photomicrograph of an SPN shows a soma $\sim 12 \mu \mathrm{m}$ in diameter that gives rise to six primary dendrites that are aspiny for the initial $20 \mu \mathrm{m}$ that then become densely invested with spines and give rise to secondary and higher-order spiny dendrites extending for a radius of $\sim 300 \mu \mathrm{m}$. 1-5, Higher-magnification images of spiny dendrites ( $\boldsymbol{A} \mathbf{2}-\boldsymbol{A} \mathbf{5})$ and axons $(\boldsymbol{A 1}, \boldsymbol{A} \mathbf{2})$ from regions marked with the same numbers in $\boldsymbol{A}$ above. Note the high density of dendritic spines. The mushroom-like appearance of many of the spines is particularly apparent in $\boldsymbol{A} 4$ and $\boldsymbol{A} \boldsymbol{5}$. The local axon collaterals are varicose and exhibit intermittent varicosities. $\mathbf{A 6}$, Whole-cell current-clamp recording of responses to intracellularly injected current pulses from this neuron is shown in $\mathbf{6}$ and is very characteristic of SPNs. B, A spiny Type I neuron shows a slightly larger soma and four thick primary dendrites that branch less frequently and follow a straighter course than the dendrites of an SPN. The dendrites are invested with spine-like appendages. These spine-like processes are of much lower density than the dendritic spines on the SPN, many of them are quite long (arrows in $\boldsymbol{B}$ ), and most appear to lack spine heads (B2). Like the SPN, the axonal arborization of the Type I neuron is quite dense. The intervaricose segments appear thinner than those of the SPN, and the entire axonal arborization is studded with larger and more prominent varicosities than that of the SPN (B1). B3, The whole-cell currentclamp recording from this neuron is typical for Type I neurons and completely distinct from that of a typical SPN.

core vesicles, but not VMAT2, which is the transporter expressed by all midbrain dopaminergic neurons (Weihe et al., 1996). It is not immediately clear what this difference means, but it could be related to the fact that striatal $\mathrm{TH}^{+}$neurons are reported to increase in number after 6-OHDA or 1-methyl-4-phenyl-1,2,3,6tetrahydropyridine (MPTP) treatment, whereas midbrain dopaminergic neurons are destroyed by these toxins (O'Byrne et al., 2000; Tandé et al., 2006; Huot and Parent, 2007). Regardless, the expression of VMAT1 by the striatal EGFP-TH ${ }^{+}$interneurons fits with previous reports claiming DAT expression in striatal $\mathrm{TH}^{+}$neurons cited above and is consistent with the possibility that the EGFP-TH ${ }^{+}$interneurons may be dopaminergic as well as GABAergic.

\section{Striatal EGFP-TH ${ }^{+}$interneurons are important components of striatal intrinsic circuitry}

Synaptic responses of striatal EGFP-TH ${ }^{+}$ interneurons resemble those of other striatal neurons. Local stimulation elicits nearly simultaneous monosynaptic glutamatergic EPSPs and GABAergic IPSPCs several millivolts in amplitude. Cortical stimulation evokes a monosynaptic glutamatergic EPSP in striatal EGFP-TH ${ }^{+}$interneurons as it does in most striatal neurons. Paired recordings revealed a connection probability of $\sim 14 \%$ for EGFP$\mathrm{TH}^{+}$to SPN connections and $33 \%$ for SPN to EGFP-TH ${ }^{+}$interneuron connections. Synaptic inputs from SPNs to GABAergic interneurons have not been reported previously in striatum, and their existence suggests that the EGFP-TH ${ }^{+}$ interneurons may play a role in synaptic integration in striatum distinct from the better known GABAergic interneurons. These data reveal that striatal $\mathrm{TH}^{+}$interneurons are well integrated into the synaptic circuitry of the striatum.

Similar to $\mathrm{PV}^{+}-\mathrm{SPN}$ synapses, synapses between EGFP-TH ${ }^{+}$interneurons and SPNs were very reliable. Two pairs (a Type I and a Type III) exhibited a failure rate of zero, and, overall, IPSC amplitudes were greater than those from axon collateral synapses. These IPSPs effectively delayed firing in SPNs. These data suggest that, similar to other GABAergic interneuronal synapses onto SPNs, those originating from EGFP- $\mathrm{TH}^{+}$interneurons may represent a particularly important and powerful source of striatal inhibition.

Relationship between striatal EGFP- $\mathrm{TH}^{+}$interneurons and striatal $\mathrm{TH}^{+}$neurons previously identified by $\mathrm{TH}$ immunostaining

It seems natural to assume that the striatal neurons that express EGFP in the EGFP- $\mathrm{TH}^{+}$mice described in this study are from 
the same population of neurons previously identified on the basis of TH immunocytochemical labeling, because EGFP expression is limited to neurons that express the endogenous TH transcriptional regulatory sequences (Heintz, 2001). Attempts to compare the morphology of striatal $\mathrm{TH}^{+}$neurons identified by immunocytochemistry and those identified by EGFP-TH ${ }^{+}$expression and then stained with biocytin are complicated somewhat by the different staining techniques and the contradictory nature of some of the previous reports. However, in general, the majority of previous studies converge to a picture of striatal $\mathrm{TH}^{+}$neurons as small- to medium-sized aspiny neurons, most likely interneurons, with varicose dendrites (Dubach et al., 1987; Tashiro et al., 1989a,b; Betarbet et al., 1997; Cossette et al., 2005; Huot and Parent, 2007), consistent with the present findings.

Biocytin-labeled Type I interneurons were medium sized with a pyramidal soma and varicose dendrites. A subset of Type I neurons exhibited slightly larger somata and were fairly densely invested with elongated, stick-like dendritic appendages. Despite the spine-like specializations, these cells were clearly not SPNs and could easily be distinguished from them morphologically (Fig. 13) as well as electrophysiologically. Nevertheless, it may be that cells of this type are responsible, at least in part, for some of the claims that striatal $\mathrm{TH}^{+}$neurons are spiny projection neurons (Darmopil et al., 2008). Although exhibiting quite distinct electrophysiological characteristics, Types II-IV could not be distinguished from one another morphologically. All exhibited medium round or ovoid somata from which issued three to four aspiny, varicose primary dendrites that branched sparingly. Neurons with this morphology have been described often in Golgi studies (DiFiglia et al., 1976; Chang et al., 1982; Bolam et al., 1983; Groves, 1983).

One fact difficult to reconcile with the assumption that striatal EGFP-TH ${ }^{+}$interneurons represent the same population of cells that were stained by $\mathrm{TH}$ immunocytochemistry in previous studies is the difference in neuron number. We found $\sim 2700$ EGFP$\mathrm{TH}^{+}$neurons/striatal hemisphere, a figure approximately one order of magnitude greater than that of striatal $\mathrm{TH}^{+}$neurons in normal rodents determined in most previous studies (Tashiro et al., 1989b; Mao et al., 2001; Busceti et al., 2008). Indeed, some investigators fail to find any $\mathrm{TH}^{+}$neurons in control striatum of rat (Meredith et al., 1999; Lopez-Real et al., 2003; Darmopil et al., 2008) or primate (Mazloom and Smith, 2006), although such neurons were readily detected after dopamine denervation with 6-OHDA or MPTP.

Furthermore, although EGFP expression and TH immunofluorescence were colocalized in a large majority of pars compacta neurons in EGFP- $\mathrm{TH}^{+}$mice, the vast majority of EGFP- $\mathrm{TH}^{+}$neurons in striatum did not exhibit TH immunofluorescence in control animals. However, after intrastriatal colchicine treatment, the number of $\mathrm{TH}^{+}$neurons immunolabeled in control mice was greatly increased, as was colocalization of EGFP and TH immunofluorescence in the transgenic animals.

These findings are likely a result of the much greater sensitivity of the BAC EGFP labeling versus immunocytochemistry for identification of TH-expressing neurons. The EGFP-TH ${ }^{+}$neurons contain multiple copies of the EGFP transgene, and the level of EGFP expression is related to the rate of $\mathrm{TH}$ transcription rather than to the level of $\mathrm{TH}$ itself (Gong et al., 2003). Thus, striatal EGFP- $\mathrm{TH}^{+}$interneurons do express $\mathrm{TH}$ but at a significantly lower level than midbrain dopaminergic neurons. Furthermore, much of the TH that is synthesized in striatal neurons seems to be transported to the terminals, thus accounting for the effects of colchicine. Thus, it seems likely that the striatal $\mathrm{TH}^{+}$ neurons identified by immunocytochemistry in normal, unle- sioned animals represent a small subset of striatal $\mathrm{TH}^{+}$neurons that have the highest levels of TH expression, whereas the majority of the EGFP-TH ${ }^{+}$neurons constitute cells with lower levels of TH expression that are usually below the threshold for detection by immunocytochemistry.

\section{Summary and conclusions}

In primates at least, several different laboratories have suggested that striatal $\mathrm{TH}^{+}$neurons also express DAT (Betarbet et al., 1997; Palfi et al., 2002; Tandé et al., 2006; Huot and Parent, 2007) and suggested that they are, in fact, dopaminergic neurons. Our experiments revealed that striatal $\mathrm{TH}^{+}$interneurons also express VMAT1, a finding consistent with this possibility. Other studies in rodents have shown that L-amino acid decarboxylase, the enzyme responsible for converting L-3,4-dihydroxyphenylalanine into dopamine, is present in a significant number of striatal $\mathrm{TH}^{+}$ neurons (Meredith et al., 1999; Lopez-Real et al., 2003), strengthening the intriguing possibility that striatal $\mathrm{TH}^{+}$neurons may be capable of synthesizing and releasing dopamine. In the present study, we have shown that four electrophysiologically distinct types of striatal $\mathrm{TH}^{+}$interneurons exist in significant numbers in the untreated mouse striatum and that these neurons make afferent and efferent GABAergic synaptic connections with SPNs. Whether these neurons can also release dopamine, and under what conditions, remain important questions for future experiments.

\section{References}

Adams JC (1981) Heavy metal intensification of DAB-based HRP reaction product. J Histochem Cytochem 29:775.

Baufreton J, Garret M, Rivera A, de la Calle A, Gonon F, Dufy B, Bioulac B, Taupignon A (2003) $\mathrm{D}_{5}\left(\right.$ not $\left.\mathrm{D}_{1}\right)$ dopamine receptors potentiate burstfiring in neurons of the subthalamic nucleus by modulating an L-type calcium conductance. J Neurosci 23:816-825.

Bennett BD, Callaway JC, Wilson CJ (2000) Intrinsic membrane properties underlying spontaneous tonic firing in neostriatal cholinergic interneurons. J Neurosci 20:8493-8503.

Betarbet R, Turner R, Chockkan V, DeLong MR, Allers KA, Walters J, Levey AI, Greenamyre JT (1997) Dopaminergic neurons intrinsic to the primate striatum. J Neurosci 17:6761-6768.

Bolam JP, Clarke DJ, Smith AD, Somogyi P (1983) A type of aspiny neuron in the rat neostriatum accumulates $\left[{ }^{3} \mathrm{H}\right]$ gamma-aminobutyric acid: combination of Golgi-staining, autoradiography, and electron microscopy. J Comp Neurol 213:121-134.

Bolam JP, Powell JF, Wu JY, Smith AD (1985) Glutamate decarboxylaseimmunoreactive structures in the rat neostriatum: a correlated light and electron microscopic study including a combination of Golgi impregnation with immunocytochemistry. J Comp Neurol 237:1-20.

Busceti CL, Biagioni F, Mastroiacovo F, Bucci D, Lenzi P, Pasquali L, Trabucco A, Nicoletti F, Fornai F (2008) High number of striatal dopaminergic neurons during early postnatal development: correlation analysis with dopaminergic fibers. J Neural Transm 115:1375-1383.

Calabresi P, Centonze D, Gubellini P, Pisani A, Bernardi G (2000) Acetylcholine-mediated modulation of striatal function. Trends Neurosci 23:120-126.

Cauli B, Audinat E, Lambolez B, Angulo MC, Ropert N, Tsuzuki K, Hestrin S, Rossier J (1997) Molecular and physiological diversity of cortical nonpyramidal cells. J Neurosci 17:3894-3906.

Chang HT, Wilson CJ, Kitai ST (1982) A Golgi study of rat neostriatal neurons: light microscopic analysis. J Comp Neurol 208:107-126.

Chesselet MF, Robbins E (1989) Characterization of striatal neurons expressing high levels of glutamic acid decarboxylase messenger RNA. Brain Res 492:237-244.

Cossette M, Lévesque D, Parent A (2005) Neurochemical characterization of dopaminergic neurons in human striatum. Parkinsonism Relat Disord 11:277-286.

Darmopil S, Muñetón-Gómez VC, de Ceballos ML, Bernson M, Moratalla R (2008) Tyrosine hydroxylase cells appearing in the mouse striatum after 
dopamine denervation are likely to be projection neurones regulated by 1-DOPA. Eur J Neurosci 27:580-592.

DiFiglia M, Pasik P, Pasik T (1976) A Golgi study of neuronal types in the neostriatum of monkeys. Brain Res 114:245-256.

Dubach M, Schmidt R, Kunkel D, Bowden DM, Martin R, German DC (1987) Primate neostriatal neurons containing tyrosine hydroxylase: immunohistochemical evidence. Neurosci Lett 75:205-210.

Gerfen CR, Wilson CJ (1996) The basal ganglia. In: Handbook of chemical neuroanatomy, Ed 12 (Swanson LW, Bjorklund A, Hokfelt T, eds), pp 371-468. Amsterdam: Elsevier Science.

Gertler TS, Chan CS, Surmeier DJ (2008) Dichotomous anatomical properties of adult striatal medium spiny neurons. J Neurosci 28:1081410824.

Gong S, Zheng C, Doughty ML, Losos K, Didkovsky N, Schambra UB, Nowak NJ, Joyner A, Leblanc G, Hatten ME, Heintz N (2003) A gene expression atlas of the central nervous system based on bacterial artificial chromosomes. Nature 425:917-925.

Gong S, Doughty M, Harbaugh CR, Cummins A, Hatten ME, Heintz N, Gerfen CR (2007) Targeting Cre recombinase to specific neuron populations with bacterial artificial chromosome constructs. J Neurosci 27:9817-9823.

Grace AA, Onn SP (1989) Morphology and electrophysiological properties of immunocytochemically identified rat dopamine neurons recorded in vitro. J Neurosci 9:3463-3481.

Graff L, Castrop F, Bauer M, Höfler H, Gratzl M (2001) Expression of vesicular monoamine transporters, synaptosomal-associated protein 25 and syntaxin1: a signature of human small cell lung carcinoma. Cancer Res 61:2138-2144.

Graveland GA, DiFiglia M (1985) The frequency and distribution of medium-sized neurons with indented nuclei in the primate and rodent neostriatum. Brain Res 327:307-311.

Groves PM (1983) A theory of the functional organization of the neostriatum and the neostriatal control of voluntary movement. Brain Res 286:109-132.

Heintz N (2001) BAC to the future: the use of bac transgenic mice for neuroscience research. Nat Rev Neurosci 2:861-870.

Hill K, Benham CD, McNulty S, Randall AD (2004) Flufenamic acid is a $\mathrm{pH}$-dependent antagonist of TRPM2 channels. Neuropharmacology 47:450-460.

Huot P, Parent A (2007) Dopaminergic neurons intrinsic to the striatum. J Neurochem 101:1441-1447.

Huot P, Lévesque M, Parent A (2007) The fate of striatal dopaminergic neurons in Parkinson's disease and Huntington's chorea. Brain 130:222-232.

Ibáñez-Sandoval O, Abercrombie ED, Koós T Tepper, JM (2007) Electrophysiology and morphology of a striatal dopaminergic neuron in mouse. Soc Neurosci Abstr 33:515.22.

Ibáñez-Sandoval O, Tecuapetla F, Shah F, Altinbilek B, Koós T, Tepper, JM (2008) Synaptic connections of striatal dopaminergic neurons. Soc Neurosci Abstr 34:179.16.

Iribe Y, Moore K, Pang KC, Tepper JM (1999) Subthalamic stimulationinduced synaptic responses in nigral dopaminergic neurons in vitro. J Neurophysiol 82:925-933.

Kawaguchi Y (1993) Physiological, morphological, and histochemical characterization of three classes of interneurons in rat neostriatum. J Neurosci 13:4908-4923.

Kawaguchi Y, Wilson CJ, Augood SJ, Emson PC (1995) Striatal interneurones: chemical, physiological and morphological characterization. Trends Neurosci 18:527-535.

Kita H, Kitai ST (1988) Glutamate decarboxylase immunoreactive neurons in rat neostriatum: their morphological types and populations. Brain Res 447:346-352.

Kita T, Kita H, Kitai ST (1984) Passive electrical membrane properties of rat neostriatal neurons in an in vitro slice preparation. Brain Res 300:129-139.

Kita T, Kita H, Kitai ST (1986) Electrical membrane properties of rat substantia nigra compacta neurons in an in vitro slice preparation. Brain Res 372:21-30.

Kitai ST, Surmeier DJ (1993) Cholinergic and dopaminergic modulation of potassium conductances in neostriatal neurons. Adv Neurol 60:40-52.

Koós T, Tepper JM (1999) Inhibitory control of neostriatal projection neurons by GABAergic interneurons. Nat Neurosci 2:467-472.
Koós T, Tepper JM, Wilson CJ (2004) Comparison of IPSCs evoked by spiny and fast-spiking neurons in the neostriatum. J Neurosci 24:79167922.

Lee CR, Tepper JM (2007) A calcium-activated nonselective cation conductance underlies the plateau potential in GABAergic neurons of the rat substantia nigra. J Neurosci 27:6531-6541.

Lopez-Real A, Rodriguez-Pallares J, Guerra MJ, Labandeira-Garcia JL (2003) Localization and functional significance of striatal neurons immunoreactive to aromatic L-amino acid decarboxylase or tyrosine hydroxylase in rat Parkinsonian models. Brain Res 969:135-146.

Mao L, Lau YS, Petroske E, Wang JQ (2001) Propound astrogenesis in the striatum of adult mice following nigrostriatal dopaminergic lesion by repeated MPTP administration. Brain Res Dev Brain Res 131:57-65.

Mazloom M, Smith Y (2006) Synaptic microcircuitry of tyrosine hydroxylase-containing neurons and terminals in the striatum of 1-methyl-4phenyl-1,2,3,6-tetrahydropyridine-treated monkeys. J Comp Neurol 495:453-469.

Meredith GE, Farrell T, Kellaghan P, Tan Y, Zahm DS, Totterdell S (1999) Immunocytochemical characterization of catecholaminergic neurons in the rat striatum following dopamine-depleting lesions. Eur J Neurosci 11:3585-3596.

Monyer H, Lambolez B (1995) Molecular biology and physiology at the single-cell level. Curr Opin Neurobiol 5:382-387.

Mura A, Linder JC, Young SJ, Groves PM (2000) Striatal cells containing aromatic L-amino acid decarboxylase: an immunohistochemical comparison with other classes of striatal neurons. Neuroscience 98:501-511.

Nisenbaum ES, Wilson CJ (1995) Potassium currents responsible for inward and outward rectification in rat neostriatal spiny projection neurons. J Neurosci 15:4449-4463.

Nishi K, Atkins PT, Surmeier DJ, Kitai ST (1990) Muscarinic regulation of cyclic AMP metabolism in rat neostriatal cultures. Brain Res 534:111-116.

O’Byrne MB, Bolam JP, Hanley JJ, Tipton KF (2000) Tyrosine-hydroxylase immunoreactive cells in the rat striatum following treatment with MPP+. Adv Exp Med Biol 483:369-374.

Palfi S, Leventhal L, Chu Y, Ma SY, Emborg M, Bakay R, Déglon N, Hantraye P, Aebischer P, Kordower JH (2002) Lentivirally delivered glial cell linederived neurotrophic factor increases the number of striatal dopaminergic neurons in primate models of nigrostriatal degeneration. J Neurosci 22:4942-4954.

Petroske E, Meredith GE, Callen S, Totterdell S, Lau YS (2001) Mouse model of Parkinsonism: a comparison between subacute MPTP and chronic MPTP/probenecid treatment. Neuroscience 106:589-601.

Porritt MJ, Batchelor PE, Hughes AJ, Kalnins R, Donnan GA, Howells DW (2000) New dopaminergic neurons in Parkinson's disease striatum. Lancet 356:44-45.

Porritt MJ, Kingsbury AE, Hughes AJ, Howells DW (2006) Striatal dopaminergic neurons are lost with Parkinson's disease progression. Mov Disord 21:2208-2211.

Rymar VV, Sasseville R, Luk KC, Sadikot AF (2004) Neurogenesis and stereological morphometry of calretinin-immunoreactive GABAergic interneurons of the neostriatum. J Comp Neurol 469:325-339.

San Sebastián W, Guillén J, Manrique M, Belzunegui S, Ciordia E, IzalAzcárate A, Garrido-Gil P, Vázquez-Claverie M, Luquin MR (2007) Modification of the number and phenotype of striatal dopaminergic cells by carotid body graft. Brain 130:1306-1316.

Sholl DA (1953) Dendritic organization in the neurons of the visual and motor cortices of the cat. J Anat 87:387-406.

Surmeier DJ, Song WJ, Yan Z (1996) Coordinated expression of dopamine receptors in neostriatal medium spiny neurons. J Neurosci 16:65796591.

Tandé D, Höglinger G, Debeir T, Freundlieb N, Hirsch EC, François C (2006) New striatal dopamine neurons in MPTP-treated macaques result from a phenotypic shift and not neurogenesis. Brain 129:1194-1200.

Tashiro Y, Sugimoto T, Hattori T, Uemura Y, Nagatsu I, Kikuchi H, Mizuno N (1989a) Tyrosine hydroxylase-like immunoreactive neurons in the striatum of the rat. Neurosci Lett 97:6-10.

Tashiro Y, Kaneko T, Sugimoto T, Nagatsu I, Kikuchi H, Mizuno N (1989b) Striatal neurons with aromatic L-amino acid decarboxylase-like immunoreactivity in the rat. Neurosci Lett 100:29-34.

Taverna S, Canciani B, Pennartz CM (2007) Membrane properties and synaptic connectivity of fast-spiking interneurons in rat ventral striatum. Brain Res 1152:49-56. 
Tecuapetla F, Koós T, Tepper JM, Kabbani N, Yeckel MF (2009) Differential dopaminergic modulation of neostriatal synaptic connections of striatopallidal axon collaterals. J Neurosci 29:8977-8990.

Tepper JM, Bolam JP (2004) Functional diversity and specificity of neostriatal interneurons. Curr Opin Neurobiol 14:685-692.

Tepper JM, Koós T, Wilson CJ (2004) GABAergic microcircuits in the neostriatum. Trends Neurosci 27:662-669.

Tepper JM, Wilson CJ, Koós T (2008) Feedforward and feedback inhibition in neostriatal GABAergic spiny neurons. Brain Res Rev 58:272-281.

Tunstall MJ, Oorschot DE, Kean A, Wickens JR (2002) Inhibitory interactions between spiny projection neurons in the rat striatum. J Neurophysiol 88:1263-1269.
Weihe E, Tao-Cheng JH, Schäfer MK, Erickson JD, Eiden LE (1996) Visualization of the vesicular acetylcholine transporter in cholinergic nerve terminals and its targeting to a specific population of small synaptic vesicles. Proc Natl Acad Sci U S A 93:3547-3552.

West MJ (2002) Design-based stereological methods for counting neurons. Prog Brain Res 135:43-51.

Wickens JR, Arbuthnott GW, Shindou T (2007) Simulation of GABA function in the basal ganglia: computational models of GABAergic mechanisms in basal ganglia function. Prog Brain Res 160:313-329.

Wilson CJ, Kawaguchi Y (1996) The origins of two-state spontaneous membrane potential fluctuations of neostriatal spiny neurons. J Neurosci 16: 2397-2410. 